\title{
Die Entstehung der Eindrücke in Geröllen.
}

\author{
Von August Kumm (Braunschweig).
}

Mit 8 Textfiguren und Tafel IV.

\section{A. Literaturverzeichnis. $\left.{ }^{1}\right)$}

1. Hutron, Theory on the earth. 1785, p. 253 (angef. bei Rothpletz 1890 [63], S. 94).

2. A. Escher von der LINTH, 1833 in O. Hger, Biographie A. Eschers vor DER LINTH (angef, bei RothPLETz [55], S. 189).

3. Fourdet, N. J. f. Miner. 1836, S. 197.

4. P. Lontet, N. J. f. Miner. 1836, S. 196-197 u. S. 339.

5. R. BuUM, Ưber einige geologische Erscheinungen in der Nagelfluh. N. J. f. Miner. 1840, S. 525-531.

6. A. Escher voN Der LINTH, N. J. f. Miner. 1841, S. 450.

7. P. LoRTet, N. J. f. Miner. 1843, S. 296.

8. H. von Decher, Sitz.-Ber. d. Niederrhein. Ges. f. Nat. u. Heilkunde 1849 (angef. bei RothPLitiz [55], S. 189).

9. A. Favre, Bull. de la soc. géol. de France, T. VII, 2. sér. 1849-50, p. 44.

10. A. Parlintre, Bull. de la soc. géol. de France, T. VII, 2. sér. 1849-50, p. $39-43$.

11. B. von Cotia, N. J. f. Miner. 1851, S. 818.

12. P. LorTET, Ann. de la soc. nat. d'agric. d'Hist. nat. et des arts utiles de Lyon 1851 (Auszug davon in NöGGERATH [14], S. 360, angef. bei RothPLETz [52], S. 361).

13. J. C. DeICKe, Über Eindrücke in den Geschieben der Nagelfluh und den Gesteinen der Quartärformation zwischen den Alpen der Ostschweiz und dem Juragebirge in Baden. N. J. f. Miner. 1853, S. $796 \mathrm{ff}$.

14. J. NögGeRATH, Die Gerölle oder Geschiebe mit Findrücken von solchen in Konglomeraten. Jahrb. d. K. K. Reichsanst. 1853, IV, S. 667-680 (angef. bei RothPLetz [52], S. 363 und bei ZIRKFr [65], S. 496).

15. B. Studer, Geologie der Schweiz, Bd. II, 1853, S. 356.

16. E. DE VERNEUT, Bull. de la soc. géol. de France, T. X, 2. sér. 1853, p. 116.

77. J. Köchln-Schlomberane, Sur les cailloux impressionnés. Bull. de la soc. géol. de Tírance, T. II, $1854-55$, p. 87.

18. N. Boubée und

19. E. HÉBERT daselbst.

29. G. BischoF, Ungleiches Verhalten schwachwirkender Auflösungsmittel auf Kalksteine. Verh. d. naturh. Ver. d. Rheinl. u. Westfalens, N. F., 2. Jahrg. 1855, S. 61 . N. J. f. Miner. 1855, S. 838.

21. H. vor Decher, Verh. d. naturh. Ver. d. Rheinlande u. Westfalens, Sitz.Ber., N. F., 2. Jahrg. 1855, S. 12-13 (angef. bei RothPLETZ [52], S. 363).

22. H. von Dechen, Daselbst. Sitz.-Ber., Jahrg. 13, 1856, S. 6 (vgl. Nr. 8).

1) Die in Klammer gesetzten Zahlen bei den Autornamen in dieser Arbeit sowie im Literaturverzeichnis beziehen sich auf die Numerierung der im Literaturverzeichnis chronologisch geordneten Arbeiten. 
23. Thurmann, Essai d'orographie jurassique 1856, p. 103 (angef. bei WaGner [89], S. 106 und bei RothPLETz [52], S. 864 ).

24. A. DaUbé́x, Expériences démonstrant la cause de la pénétration mutuelle des galets calcaires ou quartzeux dans les poudingues de divers terrains. Comptes rendus hebdom. des séances de l'acad. des sciences, T. 44, 1857 , S. 823-825 und N. J. f. Miner. 1858, S. 106.

25. A. WAGNer, Geschichte der Urwelt. 2. Aufl. 1857, S. 58 (angef. bei RothPLETZ [62], S. 94).

26. Fournet, Bull. de Ia soc. géol. de France, T. XVI, 2. sér. 1858-59, p. 1103.

27. C. F. NaUmaNn, Lehrbuch der Geognosie, 2. Aufl., I. Bd., 1858, S. 413.

28. ReIor und v. Cotta, Berg- und hüttenmännische Zeitung 1858, S. 107 (angef. bei ZIRKEL [65], S. 497).

29. G. WürtrenberGer, Über das Vorkommen von Geröllen mit Eindrücken im unteren Buntsandstein zu Frankenberg in Kurhessen. N. J. f. Miner. 1859, S. 153.

30. H. G. Brovn, Die fossilen Reste von Santa Maria, Azoren. N. J. f. Miner. 1860, S. 376.

31. J. C. Duicke, N. J. f. Miner. 1860, S. 218.

32. A. Gorut, Verh. d. niederrhein. Ges. f. Natur- und Heilkunde zu Bonn, 1860, S. 45-49 (angef. bei ZirkeL [65], S. 499 und Anmerkung in DaUbRÉE [53], S. 292 und bei RotHPLETZ [52], S. 364).

33. A. MÜLLER, Über einige anormale Lagerungsverhältnisse im Baseler Jura. Verh. d. naturf. Ges, zu Basel, Teil 3, 1860, S. 353.

34. Kaufmand, Bibl. Univ. de Genève, Arch. des sciences phys. XV, 1861, p. 140 (angef. bei ZiRKEL [65], S. 496).

35. KaufMaNs, Nagelfluhgerölle mit Eindrücken. Verh. der schweiz. naturf. Ges. 1862, S. 154.

36. H. von Dechen, Feuersteingeschiebe mit Eindxücken. Niederrhein. Ges. $f_{\text {。 }}$ Natur- u. Heilkunde zu Bonn, Sitzung rom 6. Mai 1863 und N. J. f. Miner. 1863, S. 841.

37. H. C. Sorby, Über Kalksteingecchiebe mit Einduücken. N. J. f. Miner. 186?, S. 801.

38. J. C. DeICKE, Über Eindrücke in den Geschieben der Nagelfluh und den Gesteinen der Qủartärformation zwischen den Alpen der Ostschweiz und dem Juragebirge in Baden. N. J. f. Miner. 1864, S. 315ff.

39. G. WÜRTTENBERGER, Über Eindrücke an den Bohnerzen von Salzgitter und an den in denselben vorkommenden Petrefakten. N. J. f. Miner. 1865, S. 822.

40: H. voN DwCHEN, Orographisch-geognostische Übersicht des Reg.-Bezirkes Aachen, 1866, S. 278 (angef. bei RothPLetz [ᄃ5], S. 190).

41. Dexbos und Köchuin-Schlombarger, Description géol. et miner. du dép. du Haut-Rhin, 1886, I, p. 233, 241; II, p. 50.

42. voN DǘKer, Über die Gerölle von Kohlendorf bei Neurode. Z. d. d. geol. Ges., Bd. 21, 1869, S. 251.

43. F. Römer, 46. Jahresber. d. schlesischen GeE. f. vaterl. Kultur 1E69, S. 37.

44. B. Sruder, Index der Petrographie und Stratigraphie der Schweiz und ihrer Umgebungen. Bern 1872, S. 94.

45. A. Favre, Gerölle mit Eindrücken im Diluvium der Rue de Chevaleret in Paris. Bull. de la soc. géol., 3. sér. I, 1873, p. 264.

46. C. LoRY, daselbst, p. 265.

47. Dn Rouville, daselbst, p. 265.

48. C. W. voN GüMBEL, Geognostische Durchforschurg Bayerns, 1877, S. 74 (angef. bei ZIRKEL [65], S. 499). 
49. A. HғIM, Untersuchungen über den Mechanismus der Gebirgsbildung, 1878, S. $26 \mathrm{ff}$. (angef, bei ZrRKeL [65], S. 499).

50. C. Dewalque, Sur les cailloux impressionnés du poudingue triasique de Malmedy. Ann. de la soc. géol. de Belgique, VII, 1879.

51. C. W. voN GüMBEL, Geognostische Beschreibung des Fichtelgebirges, 1879, S. 479.

52. A. RothPLETz, Über mechanische Gesteinsumwandlungen bei Hainichen in Sachsen. Zeitschr. d. d. geol. Ges., Bd. 31, 1879, H. 2, S. 355.

53. A. Dadbríx, Synthetische Studien zur Experimentalgeologie, deutsche Ausg. von A. GuRLT, Braunsehweig 1 180 , S. 291-293.

54. W. HöFgR, Mineral. und petrogr. Mitteil., II, 1880, S. 325 (angef. bei ZIRKEL [65], S. 498).

55. A. RothPletz, Über Gerölle mit Eindrücken. Zeitsehr. d. d. geol. Ges., Bd. 32, 1880, S. I89-192.

56. A. Pwrck, Die Vergletscherung der deutschen Alpen, 1882, S. 288 (angef. bei ZIRKEL [65], S. 498).

57. C. W. voN GüMret, Über die Natur- und Bildungsweise des Glaukonits. Sitz.-Ber. d. Münchener Ak. d. Wiss. 1886, S. 445.

58. A. RothPletz, Monographie der Vilser Alpen. Palaeontographica, Bd. 33, 1886, S. 69.

59. J. J. TrüH, Beiträge zur Kenntnis der Nagelfluh der Schweiz. Neue Denkschriften der allgem. schweiz. Ges. f. d. gesamten Naturwissenschaften, Bd. 30, 1888 (angef. bei ScHaAd [82], S. 47).

60. Contejean, Comptes rendus som. de la soc. géol. de France, CX, 1890, p. 811 (angef. bei ZiRKEL [65], S. 496).

61. A. Gutzwiller, Beitrag zur Kenntnis der Tertiärbildungen der Umgebung von Basel. Verh. d. naturf. Ges. zu Basel, IX, 1890, H. 1, S. 194-195.

62. A. RothPletz, Über Gerölle mit Eindrücken. N. J. f. Miner., Bd. I, 1890, S. $92-94$.

63. H. EcK, Geognostische Beschreibung der Gegend von Baden-Baden usw. Abh. d. Kgl. Pr. geol. Landesanst., N. F., H. 6, 1892, S. 482.

64. M. Reade, The Trias of Cannock Chase. Annals of Brit. Geology, 1892.

65. F. ZrRKex, Lehrbuch der Petrographie, 2. Aufl., I. Bd., 1893, S. 496.

66. TH. Fucrs, Über die Natur und Entstehung der Stylolithen. Sitz.-Ber. d. K. Akad. d. Wiss., math.-nat. Kl., Wien 1894 (angef. bei WAGNER 1913 [89], S. 110).

67. E. Rrecke, Über das Gleichgewicht zwischen einem festen, homogen deformierten Körper und einer flüssigen Phase, insbesondere über die Depression des Schmelzpunktes durch einseitige Spannung. Nachrichten v. d. Kgl. Ges. d. Wiss. zu Göttingen. Math.-phys. Kl. 1894, Nr. 4, S. 278-284.

€8. W. S. GResLy, The indentation of the bunter pebbles. Geol. Magazine, new ser., Dec. IV, II. B., 1895, p. 239.

69. M. READE, daselbst, p. 239.

70. M. Reade, Pitted pebbles in the Bunter Conglomerate of Cannock Chase, daselbst, S. 341.

71. C. W. voN GÜMBณL, Erläuterungen zu dem Blatte Speyer der geogn. Karte von Bayern, 1897, S. 16.

72. L. Rort.res, Note complementaire relative à l'excursion du 4. sept. 1897 à Roppe, près Belfort. Bull. de la soc. géol. de France, 3. sér., t. 25, 1897.

73. L. RoLLIER, Zur Kenntnis der tertiären Süßwasserkalke. N. J. f. Miner., I. Bd., Jahrg. 1897, S. 214-215.

74. G. Sternmann und F. GraefF, Erläuterungen zu Blatt Hartheim-Ehrenstetten der geol. Karte von Baden, 1897, S. 22.

75. F. BECKE, Über Mineralbestand und Struktur der kristallinischen Schiefer. Denkschriften der math.-nat. Kl, d. Akad. d. Wiss., Wien 1903. 
76. E. Kayser, Lehrbuch der allgemeinen Geologie, 2. Aufl. 1905, S. 496-497.

77. J. Koenrgsberaer und Wolf J. MüLler, Versuche über die Bildung von Quarz und Silikaten. Zentralbl. N. J. f. Miner. 1906, S. 339 und 353.

78. F. Pockels, Bemerkungen zu den theoretischen Arbeiten von P. PavLow über das Wachstum und die Auflösung der Kristalle. Zentralbl. f. Miner. Jahrg. 1906, S. 664-667.

79. A. Fixduax, Einführung in die Phasenlehre und ihre Anwendungen. Handbuch der angewandten physikalischen Chemie, Bd. VI, Leipzig 1907.

80. A. Tonnquist, Beobachtungen an Geröllen im Hauptkonglomerat des Buntsandsteins von Lascemborn in Lothringen. v. KoENwN-Festschrift, Stuttgart 1907, S. 209-220.

81. E. Wenschenk, Grundzüge der Gesteinskunde, II. Teil, 1907, S. 240.

82. E. SchaAd, Die Juranagelfluh. Beiträge zur geol. Karte der Schweiz, N. F., XXII. Lief., Bern 1908, S. 45, 47-49.

83. L. VAN WERVEKE, Zur Geologie der mittleren Vogesen und der Umgebung von Kaysersberg. Mitteil. d. phil.-math. Ges. v. Elsaß-Iothringen, Bd. III, 1903-1907, Straßburg 1908, S. 231.

84. L. v. Ammon, Erläuterungen zu dem Blatte Kusel (Nr. XX) der geognost. Karte von Bayern, 1910, S. 92, Fig. 30.

85. H. CLoos, Tafel- und Kettenland im Baseler Jura und ihre tektonischen Beziehungen nebst Beiträgen zur Kenntnis des Tertiärs. N. J. f. Miner., Beilage-Bd. 30, 1910, S. 145.

86. H. Rosmrbusor, Elemente der Gesteinslehre, III. Aufl., Stuttgart 1910, S. $493-494$.

87. E. HaUG, Traité de Géologie, I, 1911, p. 363.

88. E. RrEOKE, Zur Erniedrigung des Schmelzpunktes durch einseitigen Zug oder Druck. Zentralbl. f. Miner. 1912, p. 97.

89. G. WAGNER, Stylolithen und Druoksuturen. Geol. u. paläontol. Abhandl., N. F. XI, Heft 21, 1913, S. 1-30.

90. F. Bernauer, Gekritzte Geschiebe aus dem Diluvium von Heidelberg. Jahresber. u. Mitteil. des oberrhein. geol. Vereins, N. F., Bd. 5, Jahrg. 1915, H. 1, S. $26-29$.

91. P. NrGGLI, Über die Koexistenz von Phasen, welche versehiedenen Drucken unterworfen sind. Zeitschr. f. anorg. Chemie, Bd. 91, 1915, S. 107-133.

92. A. Heтm, Geologie der Schweiz, Lief. 1, Leipzig 1916, S. 58-61 und 69.

93. W. SALOMON, Ưber die Entstehung von »Rillensteinen «. Zeitschr. der deutsch. geol Ges., Bd. 68, Jahrg. 1916, Monatsberichte Nr. 1-3, S. 21-26.

94. W. Dewcke, Geologie von Baden, 2. Teil, Berlin 1917, S. 473-474.

95. E. KAYSER, Lehrbuch der allgemeinen Geologie, 5. Aufl. 1918, S. 681-682.

Außer diesen genannten Autoren haben sich noch einige andere, über deren Arbeiten es mir bisher nicht möglich war, nähere Angaben zu erhalten, mit der Entstehungsfrage der Eindrücke beschäftigt bzw. Vorkommen von solchen erwähnt. Zu nennen wären noch:

96. B. von CoтTA, der sich in seinen Geologischen Fragen auf S. 204 darüber ausgesprochen hat,

97. H. CReDner, der 1879 Gerölle von Grauwacke und Tonschiefer mit Eindrücken aus dem Rotliegenden bei Leipzig erwähnt haben soll,

98. HIRZEL, der nach НЕп schon 1825 die Eindrücke in den Geröllen der Schweizer Nagelfluh namhaft machte,

99. RAMSAY, der nach SoRBY gegen 1863 über tiefe Eindrücke in den Geschieben eines permischen Konglomerates auf der südlichen Seite des südlichen Kohlenfeldes von Staffordshire berichtete, und F. Soralor, Gillthron, JaAndy und F. MüHLBERG. 
Nachtrag zum Literaturverzeichnis.

100. C. W. จ. GüMBEL, Geognostische Beschreibung des Königreichs Bayern, I, 1861, S. 696 .

101. C. W. v. GƯMMBEL, Geologie von Bayern, I, 1888, S. 255, und II, 1894, S. 281, $180,294,313,784,1001,1002$.

102. G. Sprzia, La pressione nell' azione dell' aequa sull' Apofillite e sul vetro. Atti della R. Academia delle Scienze di Torino, vol. XXX, 1895.

103. G. SPezIA, Contribuzioni di geologia chimica. Solubilità del quarzo nelle soluzioni di silicato sodico. Daselbst vol. XXXV, 1900.

104. Contribuzioni di geologica chimica. Solubilità del quarzo nelle soluzioni di tetraborato sodico. Daselbst vol. XXXVI, 1901.

105. G. Speża, Il dinamometamorfismo e la minerogenesi. Daselbst vol. XL, 1905.

106. CH. E. WEISs, Erläuterungen zu Blatt Heusweiler. S. 12 (angef. bei KmSSLER $[111]$, S. 300).

107. P. Kessler, Die tertiären Küstenkonglomerate in der mittelrhein. Tiefebene. Mitt. Geol. Landesanst. v. Elsaß-Lothringen 1909, 7, S. 200 u. 205 (angef. bei KnssLer [111], S. 300).

108. Brawco, Schwabens 125 Vulkan-Embryonen, S. 347 (angef. bei KnssLeR [111], S. 300).

109. ANDREak, Ein Beitrag zur Kenntnis des Elsässer Tertiärs. Abhandl. geol. Landesanst. v. Elsaß-Lothringen 2, 1884, S. 309 (angef. bei Krsster [111], S. 301).

110. KIÄHN, Die Geologie der Umgebung von Colmar, 1904, S. 60 u. 87 (angef. bei KESSLER [111], S. 304).

111. P. KessLer, Ửber Gerölle mit Eindrücken. Zentralbl. f. Miner. usw. 1919, Nr. 19 u. 20, S. $300-307$.

112. C. Grebert, Palaeontologische Untèrsuchungen, Nr. 5. Belemniten mit Eindrücken. Zeitschr. f. d, ges. Naturw. Bd. IX, Nr. 10-11, S. 313-314, 1857.

\section{B. Einleitung.}

Während meiner in den Jahren 1912/13 ausgeführten, aber leider durch den Krieg unterbrochenen Studien über die Herkunft der Gerölle in den Konglomeraten des südwestdeutschen Buntsandsteins hatte ich reichlich Gelegenheit, mein Interesse auch den sogenannten "Eindrücken " in den Geröllen zuzuwenden. Außerdem habe ich auch in dieser Zeit dieselbe Erscheinung an Geröllen der tertiären und diluvialen Nagelfluh aus der Umgebung des Bodensees sowie des oligozänen Küstenkonglomerates des Letzenberges bei Ingersheim im Elsa $B$ und ein Jahr früher bereits an den Geröllen der miozänen Nagelfluh der Umgebung von Grenoble eingehend studieren können. Ferner stand mir noch reichliches Material aus den Sammlungen des Heidelberger geologisch-paläontologischen Institutes zur Verfïgung. Daß ich der Frage nach der Entstehung dieser »Eindrücke« trotz einer ganzen Reihe von Veröffentlichungen, deren Zahl bei der scheinbar einfachen Lösbarkeit verwundern könnte, und trotz der zusammenfassenden Darstellungen von Deicks, Rothrietz und Heim in dieser Arbeit noch einmal nähertreten möchte, wird veranlaßt durch den Umstand, daß die bisherigen Erklärungen erstens sich fast ausnahmslos als Vermutungen erweisen, 
zweitens sich heute noch gänzlich voneinander unterscheiden, weil die Deutungen stets nur nach Funden aus einer einzigen begrenzten Ortlichkeit, ohne genügendes Vergleichsmaterial und ohne umfassende Literaturkenntnis versucht worden waren, und drittens weil meine Versuche meines Erachtens eine Erweiterung derjenigen DaUBRÉEs bedeuten.

Meinem hochverehrten Lehrer, Herrn Geheimrat Prof. Dr. W. SALOMON, bin ich für die Anregung, meine Beobachtungen auszugestalten, sowie für das Interesse, das er meiner Arbeit entgegengebracht hat, und für die mannigfache Unterstiutzung, die mir von ihm zuteil wurde, sehr zu Danke verpflichtet. Ebenso danke ich auch Herrn Prof. Trautz für seine bereitwilligst erteilten Ratschläge und meinem Freunde, dem Assistenten MüLLERRIEd, für den Nachweis von Material und Literatur.

\section{Geschichtliches.}

\section{Mechanische Erklärungsweise.}

a) Druck-Erweichungshypothese ${ }^{\mathbf{1}}$ ).

Die ältesten Autoren, die Eindrücke in Geröllen beschrieben haben, waren größtenteils der Ansicht, daß sie allein durch die Wirkung eines starken Druckes auf die Gerölle hervorgerufen worden seien.

Hutтon $(1)^{2}$ ), der 1785 wohl als erster Eindrücke erwähnte, meinte, $\mathrm{da} ß$ die runden Gerölle in geschmolzenem Zustande gegenseitig ineinander eingefügt worden sein müßten.

LORTET (4) vermutet 1836, daß die Gerölle vielleicht bis auf eine gewisse Tiefe in einem »Bade von kohlensaurem Kalk « erweicht worden seien. FourNer (3) äußerte dazu, daß sie durch Wärme von neuem erweicht sein könnten, denn manche Nagelfluhen dürften durch Feuer Änderungen erlitten haben.

Nach BuUM (5) 1840 sollen Eindrücke in Kalkgeröllen und in kristallinen Gesteinen von Kalkgeröllen herrühren. Sehr starke mechanische Kräfte haben sie erzeugt und dabei zu Zerquetschungen und Reibungen (Rutschstreifen) geführt. Bei der Hebung der Alpen haben die Schichten sich aneinander gerieben, die Trümmer haben Rundung und Eindrücke erhalten, wobei Erweichung der Gerölle durch aufsteigende Dämpfe oder Flïssigkeit vielleicht mitgewirkt habe.

1849 nahm Paillette (10) Durchtränkung der Gerölle mit kohlensaurem Kali bei erhöhter Temperatur und darauffolgende Zerdrïckung in erweichtem Zustande an.

1) Ich habe versucht, die Ansichten der Autoren nicht allein nach den beiden Hauptunterscheidungsmerkmalen, der mechanischen und chemischen Erklärungs. weise, zu klassifizieren, sondern sie auch nach den Verschiedenheiten der Faktoren noch weiter zu gliedern, obgleich sich nicht in allen Fällen eine Einordnung ein. wandfrei durchführen läßt.

2) Über die Bedeutung der eingeklammerten Zahlen vgl. S. 183, Fußnote 1. 
FaVRe (9) hielt im gleichen Jahre die Bergfeuchtigkeit und den Druck der überlagernden Schichten für eine Erweichung und zur Erzeugung von Eindrïcken für ausreichend.

Nach STUdER (15) 1853 können Eindrücke durch anhaltenden starken Druck entstehen, wobei die oft vorkommenden Verdrehungen der Gerölle auf eine Erweichung zurückzuführen seien.

NöGGERATH (14) hielt im gleichen Jahre eine Deutung der Eindrücke noch für unsicher, aber wahrscheinlich seien sie mechanisch entstanden.

Deicke (13) nahm damals ebenfalls noch langsamen, aber anhaltenden Druck und Bewegung als Ursache an.

1854 meinte H'́BERT (19), die Quarzitgerölle ${ }^{1}$ ) KöchLIN-ScHLumBERGERs (17) sähen aus wie durch Hitze erweicht.

BouBÉ (18) glaubte dagegen, die Erweichung wäre durch Auflösung einer Kalkimprägnation erfolgt.

1855 stellte Bischof (20) Versuche an, indem er Quarz und Marmor aufeinander drückte und Eindrücke erhielt. Die Gegenwart von Wasser beförderte den mechanischen Vorgang.

von Dechen (21) nimmt 1855 sehr großen Druck in der Ostschweiz als Ursache an.

Nach Thurmand (23) 1856 befanden sich die Gerölle in spelomorphem \& Zustande.

1857 erklärte A. WAGNER (25) die Eindrücke als in einer zähweichen plastischen Masse entstanden.

Greber (112) sah im gleichen Jahre die Ursache für die Entstehung von Eindrücken von Eisenoolithkörnern in Belemnitenrostren und -Alveolen in dem Drucke, der durch Eintrocknung des schlammigen Bindemittels entstanden ist.

1858 schließt sich Fournet (26) der Ansicht Favres an.

1860 führte GoRLT (32) Eindrücke und Zerdrückung auf gewaltige mechanische Kräfte zurück, die aus der Bewegung langsam fließender zäher Schlammgletscher hervorgehen.

LoRY (46) machte 1873 die Unwahrscheinlichkeit der Entstehung durch Lösung für die Konglomerate des Dauphiné, des Rhône- und Sâonetals geltend, da die Schichten hier durch reichliches Bindemittel zu kompakt seien. Es sei daher anzunehmen, daß die Gerölle durch Druck unter Wasser ungleich erweicht und ungleich eingedrückt worden seien. Gerölle aus harten Gesteinen hätten keine Eindrücke, seien aber

1) Im allgemeinen dürfte das, was die Autoren als »Quarzgerölle « bezeichnet haben, von Quarzgängen herrühren und wohl am richtigsten als »Gangquarzitgeröll \& $\mathbf{z u}$ bezeichnen sein. Die Quarzite « der Literatur dürften dagegen meist "Sedimentquarzite \& sein. Ganz sicher ist man bei dieser Annahme freilich nicht; doch habe ich im folgenden auf Anraten des Herrn Prof. Salomor die Ausdrücke in diesem Sinne gedeutet und nur sie angewandt, abgesehen vom geschichtlichen Teil, wo ich möglichst die Originalbezeichnungen beibehalten habe. 
deformiert, gespalten und sternförmig zersprungen. Ferner seien die Eindruicke auch da am häufigsten, wo die Ablagerungen am dichtesten gepackt und am stärksten gestört seien.

Crepner (97) erwähnt 1879 aus dem Rotliegenden bei Leipzig Gerölle aus weicher Grauwacke und Tonschiefer, in denen härtere, z. T. Quarzgerölle Eindrücke verursacht haben. Tektonische Bewegungen haben sie hervorgebracht.

Im gleichen Jahre äußert RothPLETz (52), daß die Eindrücke in Quarzitgeröllen durch mechanische Dislokation der einzelnen Teilchen, durch eine Art Plastizität, hervorgerufen durch tektonischen Gebirgsdruck, entstanden seien. Das Vorkommen von Eindrücken in Quarzgeröllen, die damit nicht zu erklären wären, leugnet er. Zerdrückte Gerölle sind ihm Beweis für das Vorhandensein starken Druckes während der Entstehung der Eindrücke.

Ebenso glaubte 1895 GRESLY (68) aus dieser Erscheinung folgern zu dürfen, da $B$ die Eindrücke durch starken Druck hervorgerufen sind.

Nach Rosenbusch (86), 1910, mdeuten die Vorkommnisse in der Natur nicht auf chemische, sondern auf mechanische Ursachen \&, wofür "auch die Verbreitung derselben im gestörten Gebirge« spräche.

\section{b) Ausschleifungshypothese.}

Während PaILLetTé (10) 1849 die stark zerdrückten Gerölle ebenfalls auf eine Erweichung unter hoher Temperatur und hohem Druck zurückführte, nahm er für die weniger tiefen Eindrücke ein Ausschleifen mit Hilfe von Quarzkörnern durch zitternde Bewegung als Ursache an.

Diese letztere Ansicht teilt 1852 auch DE VERNEUIr (16) für Buntsandsteingerölle Spaniens, an denen er an den Kontaktpunkten der Gerölle Spuren von Abnutzung und Reibung bemerkt haben will.

Später taucht diese Anschauung nur noch bei GüMBEL (57) wieder auf. Er hat 1886 Eindrücke in den Eisenerzkörnchen und den Petrefaktenschalen in den Nummulitenschichten des Kressenberges beschrieben. Nähere Untersuchungen hatten gezeigt, daß die Kalkmasse der Schalen nicht zusammengedrückt wurde. Die Erzkörnchen könnten daher nicht in sie hineingedrückt worden sein, sondern hätten sich gleichsam hineingebohrt dank einer svibrierenden Bewegung, hervorgerufen durch eine schwache, aber langandauernde, wogende Flutung des Wassers «. In seiner "Geognostischen Beschreibung des Kgr. Bayern « (100) und in seiner "Geologie von Bayern «(101) vertritt GüMBEL die gleiche Anschauung auch für die Eindrücke in den Nagelfluhgeröllen.

1897 (71) sagt derselbe von den Eindrücken in Quarzitgeröllen, nachdem er das Fehlen von Druckerscheinungen festgestellt hat: ఎStatt Druck sind es Reibungs- und Ausschleifungsarbeiten des auf der Lagerstätte schwach, aber unendlich oft in zitternde Bewegung versetzten Materials. « 


\section{Mechanisch-chemische Erklärungsweise.}

a) Desaggregationshypothese.

1854 schloß KöchLiN-SCHLUMBERGER (17) aus dem Zusammentreffen von Sprüngen an Geröllen aus Quarz und Quarzit des Vogesensandsteins und einem Utberzug von kristallinem Quarz auf diesen Geröllen, daß gleichzeitig Druck und Auflösung auf sie gewirkt haben. An den Berührungsstellen habe sich der Quarz leichter als an anderen gelöst und sich später in Form des Uberzuges auf den Geröllen wieder ausgeschieden. Die Lösung an den Berïhrungsstellen sei unterstützt worden durch eine kleine Veränderung, durch Verletzung oder Pulverisierung einer sehr schwachen Schicht der Oberfläche, hervorgerufen durch einen sehr starken Druck des härteren oder vielleicht auch des spitzeren Gerölls.

FrüH (59) sprach sich 1888 dahin aus, daß die Eindrücke die Folge von Lösung mittels Kohlensäure unter Druck seien, wobei an den Berührungsstellen das Gestein zu Pulver zerdrückt und dann leichter angegriffen und gelöst wird.

Schaad schließt sich 1908 (82) dieser Ansicht an. Härte oder Löslichkeit scheinen keine große Rolle zu spielen, wohl aber der Krümmungsradius.

Eine ähnliche Anschauung haben 1897 auch Steinmans und GramFF (74) ausgesprochen. Die Gerölle hätten sich gegenseitig angebohrt, und an diesen Stellen sei die Kieselsäure gelöst worden, die sich dann um die Gerölle und Sandkörner wieder ausschied. Beide Vorgänge seien an das Vorhandensein der Hauptschwarzwald-Verwerfung geknüpft.

Der hauptsächlichste und letzte Vertreter dieser Hypothese ist Albert HeIm (92), der 1916 eine umfassende Darstellung der ganzen Erscheinung an Geröllen der tertiären Nagelfluh gegeben hat und das Resultat der bisherigen eingehenden Forschungen in folgenden Sätzen zusammenfaßt: "Die Eindrïcke sind keine direkt mechanische Erscheinung, also eigentlich keine Eindrücke. Sie sind nur mechanisch veranlaßt, aber der Vorgang selbst ist eine chemische Auflösung. Wenn die Last der überliegenden Massen auf eine Schicht von löslichen Geröllen ohne Füllung der Zwischenräume drïckt, so konzentriert sie sich auf die wenigen Berïhrungspunkte der Gerölle. Das schärfer gekrümmte Geröll desaggregiert am Berührungspunkte das stumpfere. Eine Menge mikroskopisch feiner Rißchen entsteht radial vom Druckpunkte ausgehend, eine Art Zermalmung hat sich eingestellt und arbeitet weiter. Kohlensäurehaltiges Wasser sickert durch und findet nun diese Stellen zur Auflösung am besten mechanisch vorbereitet. Der unlösliche Rüickstand bildet allmählich eine Zwischenhaut, der gelöste Kalzit hingegen setzt sich gleichzeitig als Bindemittel in die Lüicken der Gerölle. Der Prozeß geht so lange weiter, bis durch diese Umlagerung alle Hohlräume verschwunden sind und nun der Druck sich nicht mehr auf einzelne 
Berührungspunkte der Gerölle allein konzentriert. Zudem wird dabei dem Wasser mehr und mehr der freie Zutritt verwehrt. Im ganzen handelt es sich somit um eine Vermehrung der Löslichkeit durch feine Desaggregation an Punkten der Druckkonzentration. Fast ausnahmslos dringt das Geröll mit dem kleinsten Krümmungsradius an der Berührungsstelle in das mit dem größeren, $d . h$. in das flachere Geröll ein. *

KaYSER (95) schließt sich in den beiden neuesten Auflagen seines Lehrbuches aus den Jahren 1912 und 1918 dieser Auffassung an, bemerkt aber dazu unrichtigerweise, daß sie schon vor langer Zeit von SoRBY gemutmaßt sei.

\section{b) Druck-Lösungshypothese.}

SoRBy (37) hielt 1863 die Annahme einer rein mechanischen oder einər rein chemischen Einwirkung nicht für ausreichend zur Deutung aller Erscheinungen. Die Struktur des eingedrückten Geschiebes ist unter dem Eindruck nicht verschoben, was der Fall sein müßte, wenn das Gestein weich gewesen wäre, und es müßte Sprïnge aufweisen, wenn es fest gewesen war. Dagegen spricht die schwarze Zwischenhaut, die völlig übereinstimmt mit den unlöslichen Bestandteilen der Kalksteingerölle. Da aber diese Entfernung von kohlensaurem Kalk nur da stattfand, wo ein anderes Geschiebe eindrückte, während an anderen Stellen der Absatz von kohlensaurem Kalk in der Form kleinër Kalzitkristalle zu beobachten ist, so wird es sehr wahrscheinlich, daß die Lösung mehr oder weniger abhängig vom Drucke war. " Er stiutzt sich dabei auf die Untersuchungen von J. Thомson und behauptet (S. 805), daß kohlensaurer Kalk, umgeben von einer gesättigten Lösung des nämlichen Materials sich auflösen werde, wenn durch mechanische Kräfte ein starker Druck ausgeübt wird. Da, wo der Druck am größten ist, wird sich kohlensaurer Kalk auflösen, und da, wo er am geringsten, wird er wieder auskristallisieren. Ein Äquivalent dieser Erscheinung sind die Drucksuturen. Die Tatsache, daß von zwei sich berührenden Geröllen nur das eine gelöst wird, wird auf verschiedenartige Struktur derselben zurückgeführt, wobei auch die Form einen gewissen Einfluß gehabt haben mag.

Deicke (38) kam 1864 zu einem ähnlichen Ergebnis wie Sorby. Das mehr oder weniger mit $\mathrm{CO}_{2}$ geschwängerte Wasser löst kohlensauren Kalk an der gedrüickten Stelle auf, führt denselben fort und setzt ihn in Berïhrung mit Luft wieder ab. "Dieser chemische Prozeß wird durch mechanischen Druck bedeutend befördert, und der mechanische Druck ist auch noch für sich selbst bei diesem Prozesse tätig. " Auch die Eindrücke in Kieselgesteinen seien auf diese Weise zu erklären.

Nach Zirked (65), 1893, der mit SoRBY sich gegen die Annahme eines früheren plastischen Zustandes der Gerölle sowie gegen die Vorstellung einer rein mechanisch aushöhlenden Tätigkeit ausspricht, ist jedoch die Entstehung der Eindrücke in Quarzit- und Silikatgeröllen 
durch die Umwandlung mechanischer Kraft in chemische Wirkung nicht genügend aufgeklärt.

1905 nahm VAN WERVEKE (83) wenigstens für die mit Rissen versehenen Gerölle des Buntsandsteins an, daß der Druck die Auflösung begünstigt haben möge.

WEINSCHENK (81) führt 1907 nur diesen. Erklärungsversuch von Lösungsvorgängen an den besonders stark gepreßten Stellen an.

c) Druck-Wärmehypothese.

Folgende Autoren schrieben die chemische Wirkung des Druckes der durch ihn an den Druckstellen erzeugten Wärme zu.

RothPLETz (55) nimmt 1880 und 1890 (62) die Sorbysche Hypothese nur für die Kalkgerölle an, während er für die Quarzgerölle die Löslichkeit leugnet und für Quarzitgerölle eine mehr mechanische Erklärung zu Hilfe nahm. Suturähnliche Verzahnung zweier Gerölle in dem Eindruck sowie Zerdrückungserscheinungen beweisen ihm, daß die Eindrücke durch Auflösung unter Druck entstanden sind. Das Lösungsmittel, das matürlich auf die ganze Oberfläche der Gerölle einwirkt, iibt an den Berührungsstellen der letzteren infolge der daselbst vorhandenen und jede Flüssigkeit ansaugenden Kapillarkräfte eine beständig tätige, auflösende Einwirkung « aus. Die Kapillarkräfte genügten aber nicht. »Um tiefe Eindrücke zu erzeugen, ist wenigstens so viel Druck nötig, damit die Gerölle, welche durch die stattfindende Auflösung ihrer Substanz an den Berührungsflächen voneinander getrennt werden, immer wieder aneinander gepreßt werden. « Der durch das Gewicht der hangenden Schichten ausgeïbte Druck ist nicht ausschlaggebend, denn durch ihn "wären nur Eindrï ske oben und unten, nicht aber auch zugleich seitlich an den Geröllen zu erwarten, wie das ganz gewöhnlich statthat «. Erklärt wird die größere Löslichkeit von Substanzen unter Druck durch die an den Druckstellen erzeugte Wärme, die der zu lösenden Substanz zugeführt wird.

Auch KAYSER (76) sah noch in der zweiten Auflage 1905 darin das wesentlichste Förderungsmittel des Lösungsvorganges und meint mit SopBy, der aber, wie wir sahen, die Wärme gar nicht erwähnt, daß »die Eindriicke nicht sowohl durch mechanische Aushöhlung als durch chemische Lösung entstanden «sind.

Diese Auffassung von der Bedeutung des Druckes als wärmeerzeugender Faktor wurde 1913 von G. WAGNER (89) wörtlich aus KaYSER iibernommen, aber irrigerweise als Ansicht SoRBYs bezeichnet.

\section{Chemische Erklärungsweise.}

Lösungshypothese.

Schon 1836 hielt LoRTET (4) die Entstehung der Eindrücke in Kalkgeröllen durch Auflösung win einem Bade von kohlensaurem Kalke, der durch überschüssige Kohlensäure im aufgelösten Zustande erhalten 
wurde, « für wahrscheinlich. Er ist sich jedoch noch ïber die Wirksamkeit der Kohlensäure nicht recht klar; er fragt sich, ob sie an der Oberfläche lösend oder das Geröll bis auf gewisse Tiefe erweichend gewirkt habe, oder ob eine galvanische Aktion an den Berührungsstellen der Gerölle die Ursache gewesen.

1857 veröffentlichte dann DaUbRÉE (24) zum ersten Male seine für die Lösungshypothese grundlegenden Versuche. Er bewies, daß an den Berührungsstellen zweier unter einem Gewicht von $10 \mathrm{~kg}$ aneinander gedrückter Kalkkugeln in verdünnten Säuren keine Auflösung stattfand, sondern daß hier vielmehr deutliche Spitzen erhalten blieben, während sich der übrige Teil der Kugeln löste. Ließ er jedoch die Flüssigkeit nur auf die Beruihrungsstelle selbst einwirken, so fand nur hier die Auflösung statt und rief den Eindrücken ganz ähnliche Vertiefungen hervor. Am besten gelang der.Versuch, wenn man die Kugeln miteinander verkittete, so dab sie nicht aufeinander drüickten. Indem er diese Ergebnisse auf die natürlichen Vorkommen anwendet, trennt er als erster die Erscheinung der zerquetschten Geschiebe genetisch von den Eindrücken und erklärt erstere als die Folge des durch die Auflösung hervorgerufenen Zusammensitzens des Gebirges. Das Vorkommen von "Kalk- und Quarzkristallisationen " und von vKalk- und Quarzpuddingen « sind ihm Beweis dafür, daß zuerst eine Auflösung stattgefunden haben müsse. Die Versuche ergaben überdies die Bestätigung der älteren Beobachtungen an Vorkommen in der Natur, daß die "Eindrücke im allgemeinen durch den größten Krümmungsradius bestimmt « würden, wofür aber seiner Ansicht nach kein Grund vorhanden zu sein. schiene ([54], S. 293).

REICH und B. voN CotTA (28) haben 1858 diese Wirkung schwacher Säuren auf übereinander gelagerte Kalksteingeschiebe durch ihre Versuche bestätigt gefunden.

1859 wandte WüRTTENBERGER (29) diese Deutung auch auf Eindrücke von Sandkörnern, Kiesbröckchen und Kieselgeröllen in. Dolomitgeröllen an und meint, daß die Auflösung durch kohlensäurehaltiges Wasser erfolgt sei, wobei eine allmähliche, aber anhaltende Benetzung der gegenseitigen Berührungspunkte anscheinend vorausgesetzt werden müsse. Eindrücke in Bohnerzen der Kreide sowie in Petrefaktenschalen in denselben wurden 1865 (39) von ihm ebenfalls durch Auflösung ohne mechanische Einwirkung erklärt, und ebenso wie DaUBRÉE leitet er die Zerdrückungen vieler Gerölle von dem der Auflösung folgenden Zusammensetzen des Geröllagers her, wodurch die Eindrücke gestreift werden.

MÜLLER (33) sprach sich 1860 dahin aus, daß Druck allein oder Reibung nicht ausreichend seien, ədie korrodierende Wirkung kohlensäurehaltiger Gewässer ist augenscheinlich mit im Spiele gewesen «. Doch bliebe dabei noch manches rätselhaft.

FavRe (45) und DE Rouville (47) hielten 1873 die Entstehung von Eindrücken durch Auflösung an den Kontaktstellen durch Wasser, das 
durch Kapillarität dort zurückgehalten wird, bei Kalkgeröllen für erklärlich, aber nicht ebenso die Entstehung von Eindrücken in Kieselgeröllen und vor allem von Eindrücken, die von Kalkgeröllen in Kieselgeröllen hervorgerufen sind. Erst 1892 und 1895 fand die rein chemische Erklärungsweise in $R_{\operatorname{EADE}}(64,70)$ wieder einen Vertreter, der vor allem in ausfïhrlichen Darlegungen das Fehlen von Druckwirkungen in den Eindrücken nachzuweisen suchte und auch die Eindrücke in den Quarzitgeröllen als das Ergebnis von Kontaktlösung, hervorgerufen durch kapillar an den Beriihrungsstellen gehaltenes Wasser, ausspricht.

Rollier $(71,73)$ schließt sich 1897 in der Deutung der Eindrücke in Geröllen tertiärer Konglomerate der Ansicht DAUBRÉES an. Er beobachtete, daß an vielen Geröllen die Oberfläche außerhalb der Vertiefungen stärker durch die Lösungsmittel angegriffen wurde als in diesen selbst, was er auf eine stärkere Bewegung des Grundwassers zurückführt, während die Eindruicke selbst nur durch 》Sickerwasser in relativ trockenen Perioden entstanden sein mögen «.

1905 stellte VAN WERveKe (83) das Fehlen von Druckwirkungen ebenfalls an einem tertiären Konglomerat fest und kommt zu der Annahme der Auflösung durch kohlensäurehaltiges Wasser, das durch kapillare Kräfte an den Berïhrungsstellen länger als an den anderen zurückgehalten wurde und deshalb besonders hier seine lösende Kraft ausüben konnte.

Ferner hat sich 1907 TORNQUTST (80) zur Lösungshypothese bekannt. Er glaubte in dem Vorhandensein grobkristalliner Quarzausfüllung in den Eindrücken der Quarzite einen Beweis für die Wiederausscheidung der vorher aufgelösten Kieselsäure gefunden zu haben. Die der früheren Tiefenlage des Buntsandsteinkonglomerates entsprechende höhere Temperatur soll die Schwierigkeiten der Vorstellung der Auflösung von Kieselsäure wesentlich erleichtern können.

1917 hat als letzter DEECKE (94) sich für die Auflösung ausgesprochen und die Druckhypothese verworfen. Tertiärer und diluvialer Kies sollen sich "mit einer gewissen Sicherheit durch diese Eindrücke unterscheiden lassen «.

\section{Beschreibung der Eindrücke.}

a) In Kalkstein - und Dolomitgeröllen, in Versteinerungen und Kalkoolithkörnern.

Am häufigsten, bekanntesten und am schönsten ausgebildet sind die Eindrücke in Konglomeraten von Kalkgeröllen; und dementsprechend sind sie am meisten aus der tertiären Nagelfluh des Alpenvorlandes und des Juragebietes beschrieben. Nach der Angabe von HeIm (92) wurden sie zuerst 1825 von HIRzEL namhaft gemacht. HeIm hebt als charakteristische Merkmale dieser Eindrücke hervor, daß ein Geröll dicht anschließend in eine entsprechende Vertiefung des benachbarten Gerölles 
hineingreift. Eindrücke kommen in ganz verschiedener Anzahl an einem einzigen Geröll vor. Sie sind gewöhnlich einige Millimeter tief, manchmal sogar bis $2 \mathrm{~cm}$. Sie treten scharenweise auf, können in manchen Gegenden völlig fehlen und sollen ssich nur in Geröllen löslicher Gesteine « finden, gleichgüittig ob Kalkstein, Dolomit, toniger oder sandiger Kalk. Eindrücke werden sowohl durch lösliche als auch durch unlösliche Gesteine hervorgerufen. Die Oberfläche der konkaven Eindrücke ist in der Mehrzahl der Fälle rauh erodiert, während die konvexe Oberfläche der Gerölle schön glatt sein kann. Hie und da sind sogar sich ineinander verzahnende stylolithische Unebenheiten beobachtet worden. "Die Abnutzung auch des eindrückenden Geschiebes nimmt mit der Tiefe der Eindrücke deutlich zu, während sie bei wenig tiefem Eindruck kaum sichtbar ist. " Häufig findet sich ein unlösliches toniges oder tonig-sandiges, oft eisenschüssiges Gesteinshäutchen in den Vertiefungen. Ausnahmslos dringt das kleinere Geröll, d. h. das mit dem kleineren Krümmungsradius an der Bérührungsstelle, in das größere ein.

Gelegentlich findet sich auch ein dünnes Häutchen von Kalkspat in den Eindrücken (DeICKe [38], S. 317). Eindrücke können aber auch von Sandkörnern und kleinen Geröllbruchstïcken hervorgerufen werden, so daß ihr Vorkommen durchaus nicht an Konglomerate gebunden ist, deren Gerölle sich gegenseitig berühren. Die Formen dieser Eindrücke sind dementsprechend auch eckig und scharfkantig, während die der Gerölle in Geröllen meist rund bis oval sind und eine Breite von $3-4 \mathrm{~cm}$ erreichen können. Aber der Rand ist auch hier meistens scharf. Die Vertiefungen ragen in den verschiedensten Richtungen in das Geröll hinein; kleine vorspringende Zacken erheben sich in ihnen oft bis zu einer Höhe von $2 \mathrm{~mm}$. Häufig sind kleinere Eindrücke noch von ganzen Geröllen oder abgebrochenen Teilen derselben ausgefiillt.

\section{Verbreitung.}

Außer in der Schweiz kommen Eindrücke in Kalkgeröllen vor: in den miozänen Konglomeraten entlang des ganzen Außenrandes der Alpen bis in die Gegend von Digne und Marseille und bis in die Steiermark, in den miozänen und oligozänen Konglomeraten des Jura der Gegend von Basel, von Delsberg, Montbéliard und in Oberbaden, in den oligozänen Küstenkonglomeraten der oberrheinischen Tiefebene, im oberneogenen Konglomerat der Sattnitz bei Klagenfurt in Kärnten, an Dolomitgeröllen im Buntsandsteinkonglomerat von Frankenberg in Hessen. Ferner treten sie auf in Petrefaktenschalen der Schweizer Molasse, in den Nummulitenschichten des Kressenberges bei Traunstein, im Hilskonglomerat der Asse bei Wolfenbuittel und dem Hilseisenstein der Umgegend von Salzgitter. An den drei letztgenannten Orten sind die Eindrücke in Berührung mit "Eisensteinkörnchen " bzw. Eisenoolithkörnern entstanden. Ich konnte Eindrücke von Kalkkörnchen auch in Pectenschalen, den Originalen Bronss (30) in 
HaRTUNGs »Azoren « aus mittlerem Tertiärkalk von Santa Maria nachweisen. Und schließlich sind Eindrücke noch in den Rogensteinkörnern des Buntsandsteins der Asse und an den Kalkfragmenten von Reibungsbreccien in den Vilser Alpen beobachtet und beschrieben worden. Für das Diluvium wurde lange Zeit das Fehlen von Geröllen mit Eindrücken angenommen und diese Meinung öfter als Stütze für die mechanischen Erklärungsweisen herangezogen. DEECKE (94) will sogar noch 1917 »mit einer gewissen Sicherheit « durch die Eindrücke in tertiären Konglomeraten 》tertiären und diluvialen Kies « unterscheiden, obgleich DEICKE (31) schon 1860 Eindrücke im Diluvium der Schweiz nachgewiesen hatte. Die Funde haben sich inzwischen vermehrt. So beschrieb FavRe (45) ein Vorkommen in Paris; und LoRY (46) erwähnte ein von LoRTET beobachtetes Vorkommen am Saôneufer oberhalb Lyon und die Häufigkeit derselben im Dauphiné. Aus den von DE RouviLIE (47) dazu gemachten Angaben geht nicht mit Sicherheit hervor, ob es sich bei den von ihm beobachteten Geröllmassen mit Eindrücken im Hérault ebenfalls um Diluvium handelt.

1879 konnten von RoTHPLETz und GUTzWILLER (52) Eindrücke wiederum in diluvialen Geröllen der Schweiz festgestellt werden. Es handelte sich hier sowohl um umgelagerte Gerölle mit Eindruicken aus der tertiären Nagelfluh als auch um völlig frische und scharf ausgebildete Eindrücke diluvialen Alters.

Ich selbst sah während der Versammlung des Oberrheinischen geologischen Vereins in Friedrichshafen im Frühjahr 1913 in diluvialen Schottern nordöstlich des Bodensees sehr schöne Eindrücke; und es gelang mir in diesem Jahre auch Eindrücke in den Muschelkalkgeröllen des jungdiluvialen Neckarschuttkegels westlich Heidelberg zu entdecken. Fig. 3 und 5 der Tafel zeigen die mit den deutlichsten Eindriicken versehenen Gerölle aus diesen Ablagerungen. Die Eindrücke dieser Gerölle weisen fast alle eigentümliche kegel- bis rückenförmige Erhöhungen in ihrer Mitte auf, auf deren Bedeutung ịch später noch näher eingehen werde. Anfügen möchte ich hier noch, daß Eindr ücke von Geröllen nicht allein in Geröllen, sondern auch in ihrer Auflagerungsfläche vorkommen können. CLoos ([85], S. 145) beobachtete nämlich, daß die schwach geneigte Unterlage der Miozängerölle, »die Schichtfläche eines gelblich-weißen Argovienkalkes «, »derart dicht mit den bekannten napfförmigen Vertiefungen versehen « ist, $» d a ß$ offenbar fast jedes der aufruhenden Gerölle einen Eindruck hinterlassen hat《.

b)' Die Eindrücke in Sedimentquarzitgeröllen $\mathbf{1}$ ).

Nächst den Geröllen aus Kalkstein zeigen die Sedimentquarzitgerölle und Sandsteingerölle eine auffallende Häufigkeit von Eindrücken. Auch ihre Verbreitung ist eine größere; als bisher bekannt. Von den

1) Vgl. Näheres über diese Bezeichnung auf S. 189; Fußnote 1. 
Eindrücken in den ersteren unterscheiden sich diejenigen in den Sedimentquarzitgeröllen am auffallendsten durch ihre geringere Tiefe. Sie erreichen selten eine solche von $5 \mathrm{~mm}$ und sind recht oft nur so schwach angedeutet, daß die konvexe Krümmung der Gerölloberfläche in ihnen noch nicht in eine konkave umgekehrt ist (vgl. auch Fig. 2 der Tafel). Der Rand der Eindrücke ist je nach der größeren oder geringeren Glätte der Oberfläche des Gerölls mehr oder minder scharf, die Oberfläche der Eindrücke selbst ist in der weitaus größten Mehrzahl der Fälle rauh. Es scheint unter dem Mikroskope, als ob die dunkleren glasklaren Quarzpartikel vorzugsweise die Erhebungen in denselben bildeten. Nach READE (70) sollen allerdings auch glatte Eindrücke vorkommen, in denen die einzelnen Quarzkörnchen wie abgeschnitten mosaikaríg nebeneinander erscheinen.

Auch in diesen Eindrücken finden sich gelegentlich makroskopisch deutlich erkennbare Erhebungen von zum Teil kegelförmiger Gestalt. Sehr häufig sind die Eindrücke von in ihnen haftenden Teilen der die Eindrücke verursachenden Quarzgerölle erfüllt, die READE (70) sowohl wie TORNQUIST (80), wie wir später sehen werden, für Ausscheidung von Kieselsäure aus einer Lösung halten.

DeICKe (38) und READE erwähnen Eindriicke in weichen Sandsteingeröllen, die im Gegensatz zu manchen Sedimentquarzitgeröllen nicht zerquetseht sind.

\section{Verbreitung.}

Eindrücke in Sedimentquarzitgeröllen sind beschrieben worden aus dem Karbon in Spanien, aus dem Karbon von Eschweiler bei Aachen, von Kohlendorf bei Neurode und aus dem Kulm von Hainichen in Sachsen, ferner aus dem Buntsandstein in Spanien, in den Vogesen, im Schwarzwalde, von Commern und in der Pfalz sowie auch aus der Trias von England und aus der tertiären Nagelfluh der Schweiz. Bei den Angaben der älteren Autoren kann man oft im Zweifel sein, um welche Art von Geröllen es sich handelt; doch dürfte meist bei der Angabe von Eindrücken in 》Quarz «geröllen eine Verwechslung mit Sedimentquarzit vorliegen. Für den Buntsandstein kann ich noch aus eigenen Beobachtungen hinzufügen, daß Eindrücke in den Geröllen desselben fast über den ganzen Schwarzwald und die Vogesen (vgl. auch die Tabelle auf S. 217) verbreitet sind, soweit dichtgepackte Konglomerate auftreten; aber auch im Hardtgebirge (Felsen bei Obersteinbach im Elsaß und Schmaler Kopf bei Leimen) sind sie nicht allzu selten. Zieht man jedoch auch noch die Eindrücke in anderen Gesteinen der Buntsandsteinkonglomerate und die von Sandkörnern hervorgerufenen Eindrücke mit in Betracht, so kommt man zu dem Ergebnis, daß Eindrücke überall in den tonarmen Konglomeraten des südwestdeutschen Buntsandsteins vorkommen. Eindrücke in Sandsteingeröllen sind aus der Trias von England und aus der Nagelfluh der Schweiz bekannt. 
c) Die Eindrücke in Kieselschiefer -, Hornstein- und Feuersteingeröllen usw.

Von den anderen Komponenten der Geröllhorizonte des Buntsandsteins weisen vor allem die Kieselsehiefergerölle und die Hornsteingerölle typische Eindrücke, und zwar meist von Sandkörnchen hervorgerufen, auf. Manche Flächen dieser Geschiebe sind oft ganz übersät davon. Diese Eindrücke zeigen genau die gleichen Merkmale wie diejenigen, die von Geröllen hervorgerufen werden. Ihre Ränder sind glatt und die Oberflächen in den Vertiefungen meist uneben, oft befinden sich das eingedrungene Sandkorn oder abgebrochene Teile von solchen noch in ihnen. An einem Hornsteingeröll aus dem EcKschen Konglomerat im Schwarzwalde konnte ich unter dem Binokularmikroskope ebenfalls in zwei Eindrücken eine zentrale Erhebung, deren Spitze in gleicher Höhe mit der Gerölloberfläche liegt, erkennen. Kieselschiefergerölle mit Eindrücken habe ich sowohl in dem Eckschen Horizonte des Schwarzwaldes von Alpirsbach als auch im Hauptkonglomerat des Cone bei La Chapelle östlich Epinal gefunden. Letzteres zeigt auch mehrere ausgeprägte Eindrïcke von' Geröllen. Ein dichtes verkieseltes Geröll aus Kulmschiefer aus dem Hauptkonglomerat des Stöcklewaldkopfes im Schwarzwalde ist ebenfalls mit zahllosen winzigen Eindrücken versehen. Weiterhin sind an Feuersteingeröllen, die mit Lehm in einer Spalte im Eifeler Kalkstein bei Elberfeld vorkommen, typische Eindrücke beobachtet worden, und ebenso auch an Jaspisgeröllen im Diluvium und Tertiär der Schweiz.

\section{d) Die Eindrücke in Gangquarzitgeröllen ${ }^{\mathbf{1}}$ ).}

Aber auch an Gangquarzitgeröllen sind Eindrücke durchaus nicht so selten, wie bisher vermutet wurde, oder wie nach den Angaben in der Literatur anzunehmen wäre. Sie treten jedoch an Häufigkeit hinter den obengenannten Gesteinen weit zurück und sind auch bedeutend schwächer ausgebildet. Meist ist nur an kleinen weißen Flecken, den sogenannten »Druckflecken « ([84], S. 92, Fig. 30) die Stelle zu erkennen, wo die Gerölle sich berührten. Fig. 1 und 2 der Tafel zeigen einige deutliche Beispiele aus dem Buntsandstein. Die Oberfläche der Eindrücke ist im Gegensatz zu den übrigen Gesteinen meist glatt, die Eindrücke sehen wie geleckt aus, was bei der Homogenität des Gesteins nicht zu verwundern ist. Die Eindrücke sowie die »Druckflecke» heben sich durch ihre reinweiße Farbe von der übrigen Oberfläche des Gerölls ab, was auf die Entfernung des dünnen Eisenoxydüberzuges zurïckzuführen ist.

\section{Verbreitung.}

Eindrücke in Gangquarzitgeröllen wurden wohl zuerst von KöcHuiv Schlumberger (17) aus dem Vogesensandstein besonders angeführt,

1) Vgl. betreffs dieser Bezeichnung die Fußnote 1 auf S. 189. 
später erwähnt sie auch KaUTMans (35) aus der tertiären Nagelfluh und Dercke (38) als Eindrücke in Kieselgeröllen aus denselben Ablagerungen. voN DúckER (42) und RöMER (43) erwähnten sie aus dem Karbon von Kohlendorf in der Grafschaft Glatz. Ob es sich bei den Beobachtungen von FAVRE (9) um Gerölle aus reinem Quarz handelt, läßt sich nicht ersehen, ebenso ist die Natur der Gerölle Pamilettess (10) und DE Verneutls (16) aus Spanien und Ramsays (99) aus dem Perm Englands nicht mit Sicherheit zu erkennen. Es dürfte sich hier jedoch wohl nur um Sedimentquarzite handeln, obgleich auch Gangquarzitgerölle, vor allem in der Trias Spaniens, häufig sind.

Ich selbst konnte Gerölle aus Milchquarz mit deutlich erkennbaren Eindrücken bzw. mit weißen Flecken an den verschiedensten Punkten des Buntsandsteinmantels der Vogesen im Hauptkonglomerat nachweisen. Am Ostrande: bei Bergholz-Zell nahe bei Gebweiler, am Kloster St. Odilien bei Barr (vgl. Fig. 1 der Tafel), am Rabenfels bei Heiligenberg westlich Mutzig, am Solamont bei Saales, an der Ruine Hohbarr suidlich Zabern; auf der Westseite: im Plainetal, bei Bertrichamp in der Nähe von Baccarat, auf dem Mont d'Ormont bei St. Dié, auf dem Cone bei La Chapelle südöstlich und bei La Haute Verrière südlich Bruyères, zwischen Uriménil und Uzemain SSW Epinal, bei Thunimont westlich des Canal de l'Est und nördlich Remiremont. An allen diesen Punkten und außerdem noch an mehreren anderen fanden sich auch Eindrücke in Sedimentquarzitgeröllen. Utber das Zahlenverhältnis der Eindrïicke in den beiden Komponenten vgl. die Tabelle auf S. 217. Aber auch im Schwarzwalde finden sich Gangquarzitgerölle mit Eindrücken, wie das in Fig. 2 der Tafel abgebildete Geschiebe aus dem Eokschen Geröllhorizont von Schramberg-Sulgau und ein Geröll aus demselben Konglomerat von Braunberg bei Peterstal a. d. Rench mit sehr schönen Eindrücken von Sandkörnern, das ich in der Sammlung des Heidelberger Institutes vorfand, beweisen.

Es läßt sich also nach diesen Beobachtungen nicht mehr das Vorkommen von unzweifelhaften Eindrücken in Gangquarzitgeröllen ableugnen, wie es RotHPLETz noch 1879 tat.

e) Die Findrücke in kristallinen Gesteinen.

Eindrücke in kristallinen Gesteinen sind schon recht früh in der Literatur erwähnt worden, jedoch haben sie nie zu einer eingehenderen Beschreibung oder einem Deutungsversuch Anlaß gegeben.

BuUM (5) berichtete 1840 von Eindrücken in Geröllen von Granit, Syenit, Diorit, Gneis, Glimmerschiefer, »Aphanit " und Serpentin. KaUfmanN ([35], S. 454) von solchen in Granit und Gneis und fand, sdaß sogar Kalksteingerölle auf benachbarten Kieselgeröllen echte, tiefe, wohlgerundete Eindriicke hinterlassen haben «.

voN GüMBEL (51) erkannte Eindrücke an Geröllen »aus diabasartigem, sehr hartem Gestein « in mitteldevonischen Konglomeraten des 
Fichtelgebirges; EcK (63) Eindrücke von Sandkörnern in der Grundmasse von Geröllen aus Quarzporphyr im Buntsandstein des Schwarzwaldes der Gegend von Baden-Baden, eine Beobachtung, die ich durch einen Fund im Eckschen Konglomerate bei Enzklösterle bestätigen kann.

Auch Rothrletz (52) erwähnt ein Porphyritgeröll mit Eindrücken aus der Schweizer tertiären Nagelfluh.

\section{f) Die Eindrücke in Geröllen von Grauwacke, Tonschiefer,} Tuff, Bohnerz- und Eisenoolithkörnern.

Aus dem Rotliegenden bei Leipzig beschreibt CREDNar (97) Eindrücke in Geröllen aus weicher Grauwacke und Tonschiefer, ferner GüMBEL (51) Eindrücke in verhärtetem Tuff im mittleren Devon. Außerdem konnte ich an einem flachen Tonschiefergeröll in einem Konglomeratstück aus dem Oberrotliegenden von Schloß Wartenberg in der Pfalz, das sich in der Sammlung des Heidelberger Institutes befindet, mehrere kleine Eindriicke erkennen, die auch vor allem durch Herauslösen von kleinen Quarzgeröllen aufgedeckt wurden. Erwähnenswert ist noch das Vorkommen von Eindrücken in Bohnerzen der Kreide bei Salzgitter in Braunschweig und in Eisenoolithkörnchen der Nummulithenschichten des Kressenberges.

Fassen wir die mitgeteilten Beobachtungen über das Vorkommen von Eindrücken noch einmal kurz zusammen, so ergibt sich, daß sie 1. an Geröllen aus folgenden Gesteinen auftreten bzw. bisher nachgewiesen wurden: Kalkstein, Dolomit, Sandstein, Sedimentquarzit, Kieselschiefer, Hornstein, Jaspis, Feuerstein, Gangquarzit, Granit, Syenit, Diorit, Porphyrit, Quarzporphyr, Diabas, Gneis, Glimmerschiefer, »Aphanit«, Serpentin, Grauwacke, Tonschiefer und Tuff; 2. auch an Petrefaktenschalen, an Kalkfragmenten von Reibungsbreccien und an Bohnerz- und Kalk- oder Eisenoolithkörnern entstehen können und 3. aus folgenden Formationen beschrieben sind: mittleres Devon, unteres und oberes Karbon, Rotliegendes, untere Trias, Kreide, Eozän, Oligozän, Miozän, Pliozän und älteres und jüngeres Diluvium.

\section{E. Kritik der versehiedenen Hypothesen.}

Aus dem Uberblick uiber die einzelnen Hypothesen über die Entstehung von Eindrücken in Geröllen geht hervor, daß selbst bis in die neueste Zeit noch mehrere verschiedene Ansichten nebeneinander hertaufen, wenn sich auch seit den Arbeiten von Sorby, Deicke, REade und vor allem seit den Versuchen DaubréEs mehr und mehr eine Verschiebung des Übergewichts zugunsten der Lösungshypothese unter Verdrängung der rein mechanischen Erklärungsweisen geltend gemacht hat. Aber in gewisser Beziehung haben sich letztere noch in Verbindung mit der chemischen Deutung bis heute zu erhalten vermocht. Der 
Grund dafür liegt meines Erachtens darin, daß in allen bisher bekannten Vorkommen von Eindrücken neben diesen auch unbezweifelbare Druckerscheinungen wie Sprünge (cailloux étoilés) und Rutschstreifung oft an denselben Stücken auftreten, und daß ferner die Versuche DaUBRÉEs ja nur die Möglichkeit beweisen, durch Auftropfen von schwachen Lösungsmitteln auf die Berührungsstelle zweier Kalksteinkugeln den natürlichen Eindrücken ganz ähnliche Vertiefungen zu erzeugen. Der Analogieschluß von Kalkstein- auf Quarzgerölle ist uiberdies von zahIreichen Autoren nicht als vollgültig anerkannt worden. Während also für die Wirkungen eines starken Druckes unleugbare Anzeichen vorhanden zu sein scheinen, ist jedoch noch keine Antworf auf die Frage nach dem Zusammenhang zwischen diesen Druckerscheinungen und den Eindrücken gegeben worden. Als Beweis für eine an den Berührungsstellen stattgefundene Auflösung wird die sich in den Eindrücken häufig vorfindende dünne Haut, die als Lösungsrürkstand erkannt wurde, angeführt. Dies gilt jedoch nur für die Kalkgerölle, da alle übrigen fast immer einen derartigen Rückstand vermissen lassen. Man hat daher auch in dem Vorhandensein von kristallinen Ausscheidungsprodukten in Form von dünnen Kalkspatiiberzügen auf den Geröllen und in den Eindrücken der tertiären und diluvialen Kalkkonglomerate oder von Kristallfazetten von Kieselsäure auf den Geröllen der älteren Kieselkonglomerate einen Beweis für vorher stattgefundene Auflösung gerade an den Stellen der Eindrücke zu erblicken versucht. Jedoch ist auch hier die Frage nach den Altersbeziehungen zwischen Auflösung und Wiederausscheidung noch keineswegs als entschieden zu betrachten. Und da, wo mechanische Vorbereitung als Wegweiser oder begünstigendes Moment angenommen wurden, haben wir es wiederum nur mit Vermutungen über die Wirksamkeit der mechanischen Kräfte zu tun. Es erscheint mir daher angebracht, die Möglichkeit der Druckwirkungen vorerst noch einmal einer genauen Untersuchung zu unterziehen.

Die ältesten Theorien, die eine Entstehung der Eindrücke nur durch Druck allein für möglich hielten, mußten zur Verständlichmachung dieser Ansicht eine Erweichung der Gerölle voraussetzen, die entweder durch Wärme oder durch Imprägnation mit Alkalien oder auch mit der Bergfeuchtigkeit allein hervorgerufen worden sei. Diese Anschauungen mußten hinfällig werden mit dem Bekanntwerden der Vorkommen von Eindrücken im Diluvium und mit der Erweiterung der Kenntnis von der Entstehung derartiger Geröllablagerungen überhaupt. Man hatte sich dabei keine Vorstellung über die Möglichkeit des Eindringens eines Gerölls in das andere zu machen versucht, da man doch sonst hätte annehmen müssen, daß sich nur das den Eindruck empfangende Geröll in erweichtem Zustande befunden habe. Inzwischen sind reichlich Untersuchungen in dieser Richtung vorgenommen worden. Alle mit dem Erfolge, daß Druckerscheinungen in den Eindrücken selbst nicht wahrzunehmen sind. Eine Materialverdrängung hat nicht statt- 
gefunden, die Ränder der Eindrücke sind nicht wulstartig aufgequollen, Glimmerblättchen, die vom Eindruck angeschnitten werden, zeigen keine Fältelung noch Verdrückung ([71], S. 16); ebenso setzen sich feine Strukturlinien an beiden Seiten des Eindrucks im Dïnnschliff ohne Störung fort ([92], S. 60). Tiefe Eindrücke in marinen Petrefakten zeigen die äußeren Skulpturen der Schalen zuweilen nur wenig oder gar nicht verwischt ([38], S. 317). Eindrüicke von weicheren in härteren Geröllen sind durch mechanischen Druck überhaupt nicht zu erklären, ebensowenig Eindrücke mit konvexer Oberfläche. Die sogenannten "Druckflecken "sind, wie unter dem Mikroskop deutlich zu erkennen ist und wie schon weiter oben S. 199 angegeben wurde, nichts weiter als hellere Flecke, die durch Entfernung der früher das ganze Geröll überziehenden dünnen, meist rotbraunen Haut aus Eisenoxyd entstanden sind.

Andererseits sind die Risse und Sprünge, die'sich häufig an den Geröllen von Konglomeraten jeden Alters vorfinden, nur auf starke Druckwirkungen zurïckzufïhren. Sie finden sich aber nur in Schichten, die stärkeren Dislokationen durch Faltung oder Verwerfung ausgesetzt wurden. Oft gehen die Sprünge radial von einem Eindruck aus und erwecken so leicht den Anschein, als ob die Entstehung beider auf die gleiche Ursache, eben den lateralen Druck der tektonischen Bewegungen, zurückzuführen sei. Das Eindringen von härteren Geschieben in weichere mag diese Auffassung gefördert haben. Der Gebirgsdruck der auflagernden Gesteinsmassen kann nicht als hinreichend angesehen werden. Die Funde von Eindrücken im Diluvium mit oft nur geringer Decke schließen einen stärkeren Druck von oben her aus. Auch müßten dann ja die Eindrücke in älteren Konglomeraten überall verbreitet sein und schließlich würden sie sich auch an der Ober- und Unterseite der Gerölle häufiger vorfinden, bei lateralem Druck demnach vorzugsweise an den Seiten, mehr oder weniger horizontale Lagerung der einzelnen Komponenten vorausgesetzt. In den meisten Fällen sollen sie jedoch nach READE (70) auf eine Seite und auf die Ecken der Gerölle beschränkt sein. Meines Erachtens ist jedoch auf diese Beobachtung nur geringer Wert zu legen, da das Auftreten von Vertiefungen immer von der vom Zufall abhängigen Verteilung der Berührungsstellen mit den Nachbargeröllen abhängig ist. Nach demselben Autor müßte jeder Druck, der imstande wäre, die Spitze eines Gerölls in einen Quarzit hineinzudrücken, stets ein Zerbrechen des kleineren der beiden Gerölle verursachen, was wohl auf jeden Fall für die Kalkgerölle angenommen werden muß. Denn der einfachste Versuch einer Gegeneinanderpressung von zwei Kalkgeröllen oder von einem Kalk- und einem Quarzgeröll im Schraubstock zeigt, daß das eine derselben unfehlbar zerspringt, ehe sich auch nur die Spur einer wahrnehmbaren Vertiefung an ihnen zeigt. Auch PamLleTTe (10), der Pressungsversuche an Kieselgeröllen (wahrscheinlich Sedimentquarzit) unter Aufhebung der seitlichen Ausweichmöglichkeit für die Geröllbruchstiicke 
anstellte, war überrascht, stets nur Risse und Sprünge anstatt Eindrücke selbst bei geringer Drucksteigerung zu erhalten.

Der Buntsandstein Südwestdeutschlands und des anschließenden französischen Buntsandsteingebietes ist am besten geeignet, den $\mathrm{Zu}$ sammenhang zwischen den Eindrücken und der Sprungbildung erkennen zu lassen. Bekannt wurden zersprungene Gerölle aus der unmittelbaren Nähe der Hauptschwarzwaldverwerfung im Gebiete des Blattes Hartheim-Ehrenstetten und in den Vogesen vom Nordhang des Tales bei Gebweiler. Diese Fälle konnte ich noch um folgende vermehren: Das Karneolkonglomerat an der Ruine Geiersburg bei Wachenheim in der Pfalz, der Steinbruch südlich Aue bei Masmünster, die Burgruine Hohbarr suidlich Zabern und das westlichste Hauptkonglomeratvorkommen westlich der Vogesen bei Relanges. Die erstgenannten Vorkommen sind

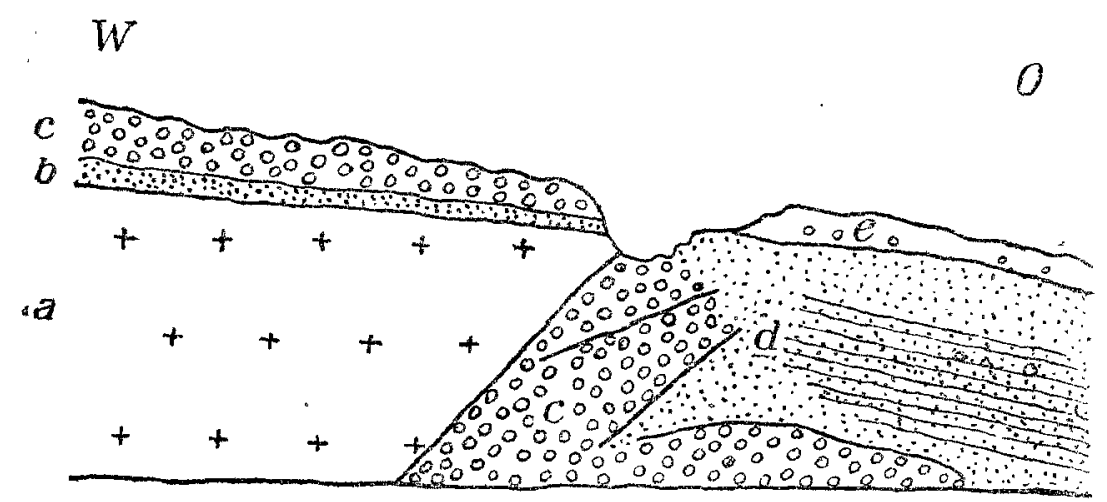

Fig. 1. Überschiebung bei Relanges nordwestl. Darney. $a$ Granit; $b$ geröllfreier, grobkörniger Sandstein; $c$ Hauptkonglomerat; Gerölle nur in der eingekeilten Zone zerquetscht; $d$ feingesehichteter Oberer Buntsandstein mit Karneolbrocken; e Verwitterungsdecke.

unmittelbar an die Verwerfungen des Ostrandes der Vogesen gebunden und liegen in relativ gehobenen oder gesenkten Schollen, sind also westlich und östlich von Verwerfungen begrenzt. Sehr charakteristisch ist der Aufschluß bei Relanges am Eintritt der Straße von Darney (WSW Epinal) nach Provenchères in den Wald. Hier ist der Granit mit auflagerndem Hauptkonglomerat auf oberen Buntsandstein überschoben. Zwischen beiden ist eine Geröllzone eingekeilt, deren Gerölle sowohl mit Eindrücken versehen, als auch stark zerquetscht sind (vgl. Textfig. 1). In dem normal gelagerten Konglomerat finden sich dagegen nur Eindrücke. Auch das von TORNQUIST ( 80 ) bei Lascemborn in Lothringen gefundene und von ihm auf Tafel 7 in Fig. 2 wiedergegebene Sedimentquarzitgeröll zeigt einen deutlichen Sprung, der auf die von TorNQUIST ausḋiicklich erwähnten, ganz in der Nähe gelegenen Verwerfungen zuriickzuführen ist. In den zwischenliegenden Gebieten, die weniger oder gar nicht von Verwerfungen durchsetzt sind, kommen wohl uiber- 
all Eindrücke, wie wir aus den weiter oben (S. 198) angeführten Fundpunkten und aus der Tabelle auf S. 217 ersehen können, nicht aber stets auch zersprungene Gerölle vor. Allerdings habe ich auch weiter vom Rheintalgraben ab auf dem Schmalen Kopf bei Leimen in der Pfalz im Karneolkonglomerat einen Block mit zahllosen zerquetschten und mit Eindrücken versehenen Geröllen gefunden. Einzelne Quarze bestehen hier nur noch aus leicht zusammengekitteten Splittern. Es ist jedoch sehr wahrscheinlich, daß auch diese Druckwirkungen entweder auf die auf Blatt Speyer ca. 1,5 km nordwestlich des Schmalen Kopfes eingezeichnete Verwerfung zurückzuführen sind, oder daß in seiner Nähe noch eine zweite, bisher nicht erkannte Verwerfung hindurchzieht.

Es muß demnach aus allen diesen Beobachtungen die Folgerung gezogen werden, daß Sprïnge und Eindrücke gelegentlich, d. h. nur in stark gepreßten Schollen oder Keilen zusammen auftreten. Daraus ist aber noch keineswegs ein Grund abzuleiten, die Entstehung beider kausal und zeitlich in Zusammenhang zu bringen und mit dem durch die tektonischen Bewegungen hervorgerufenen lateralen Druck zu erklären.

Es könnte jedoch immer noch der Einwand geltendgemacht werden, daß Sprïnge und Eindrücke nur als Wirkungen einer verschiedenen Druckstärke zu betrachten seien, die naturgemäß an den Verwerfungsund Überschiebungsflächen größer ist als in einiger Entfernung von ihnen.

Hinfällig wird jedoch dieser Einwand durch Betrachtung der Vorkommen von Eindrücken im Diluvium. Aus den Angaben von Forriet und DE RouviLLE geht nicht hervor, ob es sich um gestörtes oder ungestörtes Gebiet handelt. In dem von RoTHPLETz ([55], S. 190) beschriebenen Vorkommen ist jedenfalls seitlicher Gebirgsdruck wirksam gewesen, denn zusammen mit den Eindrücken kommen auch zerdrïckte Gerölle vor. Der Druck, der zu Zerquetschungen führte, kann »keinesfalls aus dem Gewicht der darüberliegenden Gesteinsmasse hergeleitet werden «, da die Mächtigkeit derselben sehr gering ist. Aber als ausschlaggebend sind jedoch die Funde von Kalkgeröllen mit Eindrücken $\mathrm{zu}$ erachten, die mir Anfang dieses Jahres in zwei Kiesgruben im jungdiluvialen Neckarschuttkegel westlich Heidelberg gelungen sind. Einige Gerölle von verschiedener Größe (die schönsten sind in Fig 3 und 5 der Tafel abgebildet) zeigen unzweifelhafte Eindrücke. Zum Teil sind sie direkt dem Anstehenden entnommen, so daß sich hier die Mächtigkeit der überlagernden Schicht mit $2,5 \mathrm{~m}$ genau angeben läßt. Füur die übrigen kann sie im Maximum bis zu $8 \mathrm{~m}$ betragen haben. Druckerscheinungen sind in der gesamten Ablagerung nicht zu erkennen, abgesehen von untergeordneten Schrammungen, die auf Eisstauungen zurückzuführen sind (90). Es steht also fest, daß Eindrücke in Geröllablagerungen auftreten, die nie einem stärkeren Drucke ausgesetzt gewesen sind. 
Aus später zu besprechenden Erscheinungen (siehe S. 209) an den Eindrücken selbst und aus den unter Druck angestellten Auflösungsversuchen lassen sich ebenfalls noch Beweise für das Fehlen einer mechanischen Wirksamkeit des Druckes während der Bildung der Eindrücke ableiten. An Stelle dieser »abstoßenden «Idee von der Entstehung der Eindrücke in Quarzgeröllen allein durch Druck (KöchLIN-SchLUMBERGER [17]) mußte also eine andere Hypothese treten, die den Erscheinungen eher gerecht werden sollte.

Diejenige, die die Eindriucke noch auf rein mechanische Vorgänge zurückführt, möchte ich mit der Bezeichnung "Ausschleifungshyp othese belegen.

Charakteristischerweise ist sie allein auf die quarzitischen Gerölle angewendet worden. PaILLETTE (10) will in der Zerstörung der Politur in den Eindrücken Anzeichen von Abnutzung durch den Ausschleifungsprozeß unter Beihilfe von Quarzsand sehen; jedoch müßte an Eindrücken gerade das Gegenteil, nämlich eine Glättung ähnlich der bei den Rutschstreifen entstehen, die sich ausnahmslos an allen Eindrücken zeigen müßte, und die Eindriicke wären bei drehender Bewegung alle rund. Beweise, die die Annahme einer ausschleifenden Bewegung stiutzen könnten, sind nie erbracht worden und lassen sich vor allem für die Kalkgerölle nicht erbringen, da bei ihnen die Härteunterschiede nach ScHaAd ([82], S.47) keine Rolle spielen sollen. Auch wäre die mehrfach beobachtete Tatsache, daß Gerölle aus weicheren Gesteinen in solchen von härteren Eindrücke erzeugt hätten, danach gänzlich ausgeschlossen. Vor allen Dingen kann diese Hypothese niemals als eine Erklärung für diejenigen Eindrücke angesehen werden, die mehr oder minder starke Erhebungen oder stylolithische Verzahnungen aufweisen.

Ein von SALOMON am Bahndamm vom Rigihang zwischen Küßnacht and Arth gesammeltes Quarzitgeröll mit ausgezeichneten tiefen Eindrücken und zahllosen Eindrücken von Sandkörnern läßt in denselben unter dem Mikroskop kleine, weiche, hervorragende Glimmerblättchen erkennen, die bei einer Ausschleifung völlig verrieben oder zerdrückt worden sein müßten. Dasselbe müßte auch der Fall gewesen sein an einem Kalkgeröll der Rigi-Nagelfluh, in dessen Eindrücken sich mehrfach kleine, mehr oder minder hervorragende Körner befinden, die in den großen Eindrücken kleine akzessorische Eindrücke erzeugt haben.

Alle übrigen Hypothesen haben sich einer Zuhilfenahme von chemischer Auflösung an den Berïhrungsstellen nicht verschließen können, ja, sie haben diese als das Wesentliche des Vorganges angesprochen. Sie war schon sehr frühzeitig gemutmaßt worden. Jedoch glaubten zahlreiche Autoren auf die Mitwirkung eines Druckes insofern nicht verzichten zu können, als sie in den Druckwirkungen die Beantwortung der Frage zu sehen meinten, warum die Auflösung sich nur oder fast ausschließlich an den Berührungsstellen der Gerölle wirksam gezeigt habe. Offenbar gehen die Anhänger der kombinierten Anschauungen 
von der gleichzeitigen Wirksamkeit von Druck und Auflösung von der Voraussetzung aus, daß die eindrückeführenden Konglomerate völlig mit einer Flüssigkeit durchtränkt gewesen seien, eine Vorstellung, die allerdings die Schwierigkeit einer Erklärung der lokalen Beschränkung der Auflösung auf die Berïhrungsstellen in sich trägt. Der Kapillarität wird nur teilweise eine noch untergeordnete Bedeutung zugeschrieben. Drei verschiedene Hypothesen lassen sich unterscheiden je nach der Wirkung, die man vom Druck erwartet bzw. für ausschlaggebend hält:

Das ist

1. die mechanisch-zerstörende Wirkung,

2. die wärmeerzeugende Wirkung,

3. die löslichkeitssteigernde Wirkung des Druckes.

Die erste möchte ich nach einem von Herm gebrauchten Ausdruck Desaggregationshypothese nennen. Sie wurde sowohl auf Kieselkonglomerate als auch auf die Kalkkonglomerate angewendet und besagt, daß das eine Geröll an der Berührungsstelle die Oberfläche des anderen zu feinem Pulver zerdrückt hätte, und daß dann an den so vorbereiteten Punkten das Lösungsmittel leichter angreifen konnte. KöcrrLIN-SCHLUMBERGER (17) vermutete, daß von dem härtesten oder dem spitzesten Geröll diese Desaggregation der Oberfläche des anderen ausgegangen sei, eine Vermutung, die von HErm (92), HöFER (54) und anderen insofern bestätigt wurde, als sie für erwiesen halten, daß fast ausnahmslos das Geröll mit dem kleineren Krümmungsradius an der Berührungsstelle in das mit dem größeren, d. h. das flachere Geröll, eindringe. Es ist hier zum erstenmal der Versuch gemacht, das verschiedene Verhalten der beiden Gerölle dem Lösungsmittel gegenüber zu erklären.

Hiergegen lassen sich aber zum Teil die gleichen Einwände erheben wie gegen die Druckhypothese überhaupt. Diese feine Zersplitterung der Oberfläche besteht nur in der Vorstellung, nachgewiesen wurde sie bisher noch nicht; ebensowenig ist zu erklären versucht worden, warum sie nur an dem einen Geröll und nicht an beiden hätte auftreten sollen. Ferner stößt der Gedanke, daß diese Desaggregation noch fortgedauert hätte, während schon ein Eindruck von einer gewissen Tiefe entstanden war, auf Schwierigkeiten. Denn mit der Tiefe des Eindrucks vergrößert sich naturgemäß die Berïhrungsfläche der beiden Gerölle, und eine entsprechend stärkere Kraft wäre notwendig, um auf dieser gesamten Fläche die Desaggregation zu erzeugen.

Diese Ansicht setzt ferner voraus, daß der Druck in den Konglomeraten auch nach den Seiten hin in gleicher Weise wirksam gewesen sei, was jedoch meines Erachtens mit gewissen Schwierigkeiten verbunden sein dürfte. Denn hat die Auflösung in den mehr seitlich gelegenen Berührungsstellen der Gerölle erst einen gewissen Grad erreicht, so müßten die Gerölle sich durch eine seitliche Bewegung wieder genähert haben, um von neuem der Auflösung einen Anstoß zu geben. Die seitliche Be- 
wegung könnte aber nur in einer Richtung erfolgt sein, so daß das einzelne Geröll nur auf zwei Seiten tiefere Eindrïcke empfangen haben könnte, wenn man eine Bewegung der Gesamtheit der Gerölle in dieser einen Richtung annehmen will. Das würde aber wiederum Eindrücke an den senkrecht zu dieser Bewegungsrichtung gelegenen Berïhrungspunkten ausschließen. Tektonische Vorgänge wären als Ursache dieser Vorgänge anzusehen, wogegen die Last der überliegenden Massen, die Hетм als Kraftfaktor annimmt, vor allem in den $z$. T. wenig mächtigen diluvialen Geröllablagerungen nicht als hinreichend anzusehen sein dürfte.

Dislokationen aber, die einen derartigen Druck auf die Gerölle ausiiben, daß die Oberfläche der Eindrücke desaggregiert werden könnte, würden wohl stets zu einem Auseinandertreiben und Zerbrechen des eingedrückten Gerölls führen, zumal wenn der Druck von zwei oder mehreren Eindrucksstellen aus wirkt.

Abgesehen davon, daß Beispiele genug bekannt sind, wo Gerölle auf allen Seiten mit Eindrücken versehen sind, ja ringsherum oft förmlich mit Sandkörnern und Kiesbröekchen gespickt sind, und daß ferner diese Anschauungsweise auf alle die Fälle nicht anwendbar ist, wo Eindrücke von weicherem Gestein in härterem hervorgerufen wurden, läßt sich vor allem durch Lösungsversuche an zusammengepreßten Geröllen zeigen, daß die Lösung gar nicht von den Berührungsstellen ausgeht.

DAUBRíE hatte in seinen bekannten Versuchen zwei Kalksteinkugeln, die mit einem Gewicht von $10 \mathrm{~kg}$ belastet waren, in schwach angesäuertes Wasser gelegt. Der Erfolg war, daß sich der Kalk an der gesamten Oberfläche der Kugeln auflöste mit alleiniger Ausnahme ihrer Berührungsstellen. Beide Kugeln zeigten hier eine sehr deutliche Spitze.

Um dem Einwande zu begegnen, daß dieser Druck von $10 \mathrm{~kg}$ entweder zu stark oder zu schwach gewesen sei, habe ich den Versuch unter entsprechend verschiedenen Bedingungen wiederholt.

\section{Eigene Versuche.}

Ich habe zwei Muschelkalkgerölle zwischen zwei Eisenplatten durch zwei Schrauben so stark gegeneinander gepreßt, daß gerade noch ein Zerspringen der Gerölle vermieden wurde, und das Ganze in verdüinnte Salzsäure getaucht. Je nach dem Grade der angewandten Verdünnung zeigten sich die beiden Kegel schon nach einigen Stunden oder erst nach mehreren Tagen.

Es lag die Vermutung nahe, anzunehmen, daß bei längerer Dauer des Versuches die Kegel immer spitzer und kleiner werden und daß sie durch den andauernden Druck zerquetscht würden. Ich habe daher den gleichen Versuch im Schraubstock wiederholt, aber diesmal nicht zwei Kalkgerölle, sondern ein Kalkgeröll und eine Metallkugel gegeneinander gedrückt, da sich im ersteren Falle der Druck nur sehr schwer so regulieren ließ, daß ein Zerspringen eines der beiden Gerölle immer 
zu vermeiden gewesen wäre. Verdünnte Salzsäure wurde auf die Berührungsstelle ständig in größeren Pausen aufgetropft und durch vorsichtiges Anziehen der Schraube der entstandene Kegel zerquetscht. Der Versuch wurde fortgesetzt, bis die Kugel zur Hälfte in das Geröll eingedrungen war. In dem so entstandenen Eindruck zeigten sich aber wiederum zwei deutliche etwas gestreckte Erhebungen, deren Spitzen allerdings abgequetscht waren. Diese Erhebungen zeichneten sich durch eine hellere Farbe gegenüber dem uibrigen Teil des Eindrucks aus. Die Ursache dafür ist in der mikroskopisch feinen Zersplitterung an der Oberfläche dieser Erhebung zu erkennen.

Also trotzdem hierdurch alle Voraussetzungen der Desaggregationshypothese erfüllt scheinen, ist gerade das Gegenteil von dem, was erwartet werden sollte, eingetreten.

Ferner habe ich die Auflösung auch an Geröllen versucht, die nur lose aufeinander oder aneinander gelegt waren, und habe dabei einmal das Lösungsmittel auf die Berührungsstellen aufträufeln lassen und ein andermal durch eine auf die Gerölle aufgelagerte Sandschicht hindurchsickern lassen.

Es zeigte sich fast an jeder Benetzungsstelle, meist an beiden Geröllen, eine ringförmige Vertiefung mit einem kleinen Zentralkegel bzw. ein Ring von kleinen Lösungsgrübbchen mit der unangegriffenen Berührungsstelle in der Mitte.

Man erkennt also in allen Fällen den Vorgang bei der Lösung aufs deutlichste: nicht an den Berührungsstellen (gleich Druckstellen) greift das Lösungs mittel an, selbst wenn eine feine Zersplitterung an derselben erzeugt wurde, sondern in dem mehr oder weniger ringförmigen kapillaren Hals um die Berührungsstelle herum.

Ich habe nun daraufhin sämtliche mir zur Verfügung stehenden Gerölle mit Eindrücken z. T. mit Hilfe des Binokularmikroskops auf derartige Erscheinungen untersucht und fand sie sehr schön ausgebildet an einem Gangquarzitgeröll aus dem Buntsandstein vom Solamont bei Saales. Dieses Stiick ist mir aber leider während des Krieges abhanden gekommen.

Weniger scharf ausgeprägt sah ich sie an den Sedimentquarziten; sie kommen jedoch auch an ihnen in deutlich erkennbarer Form vor, wie an den beiden von Torneurst ([80], Tafel 7, Fig. 1 und Fig. 2) reproduzierten Sedimentquarzitgeröllen aus dem Buntsandstein von Lothringen ausgezeichnet zu erkennen ist. Die betr. Eindrücke befinden sich beide im rechten unteren Quadranten der Abbildungen, und zwar bei Fig. 1 in einem Abstande von $17 \mathrm{~mm}$ und bei Fig. 2 von $4 \mathrm{~mm}$ vom unteren Bildrande entfernt. Sie zeigten sich ferner typisch an winzigen Eindrücken von Sandkörnern in dem S. 199 erwähnten Hornsteingeröll and an dem S. 200 erwähnten Gangquarzitgeröll aus dem Buntsandstein des Schwarzwaldes, an einem schwachen Eindruck eines Juranagelfluh- 
gerölls von Tuttlingen und an mehreren Kalkgeröllen aus dem jungdiluvialen Neckarschuttkegel (vgl. Fig. 3, 4 und 5 der Tafel).

Nirgends fanden sich an diesen abgestumpften Kegeln, die z: T. noch die Höhe und die Beschaffenheit der alten Gerölloberfläche an ihrer Spitze aufwiesen, auch nur die geringsten Spuren einer Zersplitterung.

Vermutlich gehören auch die von ScH.AAD ([82], S. 47 und 48) beschriebenen und im Querschnitt abgebildeten zackenförmigen Erhebungen hierher. Ich selbst konnte an alpinen Nagelfluhgeröllen aus der Sammlung des Heidelberger Institutes nur in wenigen Eindrücken kleine regelmäßige Erhebungen entdecken, die sich jedoch nicht immer in der Mitte derselben befanden. Auch die von Herm ([92], S. 59) abgebildeten Eindrücke zeigen teilweise geringe Erhebungen, die sich leicht als Reste von Berührungskegeln deuten lassen. Besser zeigt sich diese Erscheinung an einigen tieferen Eindrïcken des obenerwähnten Juranagelfluhgerölls von Tuttlingen. Andererseits kommen auch in den von mir untersuchten Eindrücken sehr schmale leistenförmige Erhebungen vor, die sich quer durch die Vertiefung in geringerer Erhöhung hindurchziehen. Sie deuten ebenfalls auf das Fehlen eines desaggregierenden Druckes hin. Des weiteren ließe sich vielleicht noch einwenden, dab es durch die innige Berührung zwischen eindringendem und eingedrücktem Geröll, wie sie die Desaggregationshypothese voraussetzt, vor allem bei Vorhandensein eines tonigen Lösungsrückstandes in der Vertiefung, dem Lösungsmittel gänzlich unmöglich gemacht wäre, zwischen die beiden Gerölle einzudringen und hier lösend zu wirken. Die durch den Druck eventuell entstandenen feinen Risse würden durch das tonige Zwischenhäutchen völlig verschlossen werden.

Solange also eine Berührung zwischen zwei Geröllen, ein Druck von irgendeiner beliebigen Stärke, der nicht zum Zerspringen des einen Gerölls führt, wirksam ist, befindet sich an dieser Stelle keine Flüssigkeit, und infolgedessen erfolgt auch keine Auflösung.

Es ist ferner anzunehmen, daß mit fortschreitender Auflösung die Erhöhungen von der Seite her mehr und mehr aufgelöst werden, bis sie schließlich ganz verschwinden. Stehen die Gerölle jedoch unter dauerndem Druck, so muß sich auch ein Berührungskegel so lange erhalten, wie überhaupt Auflösung stattfindet.

Das Fehlen der Berührungskegel in der weitaus größten Mehrzahl der Eindrücke ist de mnach ein Beweis für das Fehlen jeder Druckwirkung überhaupt während der Entstehungs zeit der Eindrücke.

Alle unzweifelhaften Druckerscheinungen wie Sprünge, Rutschstreifung und Glättung sowie das Einpressen des einen Gerölls in den Eindruck des anderen sind daher in eine spätere Zeit als die der Entstehung der Eindrücke zu verweisen. 
DaB jene Kegel am schönsten in den jungdiluvialen Schottern und an den Quarzitgeröllen ausgebildet sind, dürfte allein von der Jugend der ersteren und der geringen Löslichkeit der letzteren abhängen.

So wie das Fehlen von Berührungskegeln einerseits ein Beweis für die Entbehrlichkeit des Druckes sind, so ist das gelegentliche Vorhandensein derselben andererseits ein Beweis für die Wirksamkeit einer rein chemischen Auflösung, und zwar nicht nur an Kalkgeröllen allein, sondern auch, was im Hinblick auf die bisherige Literatur von größerer Bedeutung ist, an den Kieselsäuregesteinen.

\section{Druck-Wärmehypothese.}

Was hier über die mechanische Wirksamkeit des Druckes gesagt ist, gilt naturgemäß z. T. auch für die übrigen Hypothesen, die des Druckes zur Verständlichmachung einer stattgefundenen Auflösung an den Berührungsstellen $\mathbf{z a}$ benötigen meinen. Es ist klar, daß der Wärmesteigerung und der Löslichkeitserhöhung durch Druck in den jungdiluvialen Schichten überhaupt kein Wert beigelegt werden kann.

Fiir die größte ehemalige Tiefenlage der Buntsandsteinkonglomerate berechnet ToRNQUIST ([80], S. 217) eine Temperatur von 45 Grad, die er für ausreichend hält, um in langen geologischen Zeiträumen merkbare Einwirkungen zu erzielen. Es ist dagegen einzuwenden, daß nichts dafür spricht, daß die Auflösung in jener Zeit vor sich gegangen wäre (vgl. Näheres hierzu auf S. 214 und 219).

Wird von tektonischen Bewegungen Druck hervorgerufen, so mag der erzeugten Wärme eine lösungsbefördernde Wirkung zugesprochen werden, die aber einerseits für die Entstehung der Eindrücke nicht in Frage kommt, da beide nicht zeitlich zusammenfallen (vgl. S. 205 u. 210), und andererseits auch nach den Versuchen von KöNIGSBERGER und MüLLER (vgl. S. 212) wenigstens für Kalziumkarbonat nicht zutrifft.

\section{Druck-Lösungshypothese.}

Dem Druck als solchem ${ }^{1}$ ) ist ebenfalls bei gleichbleibender Temperatur theoretisch ein wenn auch wenig auffallender Einfluß auf die Löslichkeit von festen Körpern zuzuschreiben.

Nach dem Satze von Le ChatelizR muß Vergrößerung des Druckes die Löslichkeit erhöhen, wenn sich ein fester Körper mit Volumverminderung löst, und umgekehrt vermindert sich die Löslichkeit, wenn die Lösung unter Volumvermehrung stattfindet ([79], S. 66).

Nach einer freundlichen Mitteilung des Herrn Prof. Trautz ist aber das Verhalten von Kalziumkarbonat in bezug auf Volumänderung beim Ubergang in den gelösten Zustand bisher noch nicht festgestellt worden, so daß alle Annahmen von einer Erhöhung der Löslichkeit nichts als reine Vermutungen sind. Das Gegenteil kann ebensogut möglich sein.

1) Im Sinne von gleichem hydrostatischen Druck ([91], S. 119). 
Uberdies ist die Änderung der Löslichkeit bei den bisher untersuchten Mineralien selbst bei bedeutender Zunahme des Druckes (z. B. 500 Atmosphären) eine sehr geringe, was sseinen Grund in der geringen Volumänderung hat, die die Lösung bei zunehmendem Druck erleidet « ([79], S. 67).

Tatsächlich haben denn auch nach KöNIGsBergeR und MüLler ([77], S. 343) zahlreiche Messungen und Versuche, von denen besonders die von SPEzIA (102-105) angestellten genannt werden mögen, sowie die Theorien der physikalischen Chemie ergeben, daß der Einfluß des Druckes auf chemische Prozesse ein äußerst geringer ist». Fiur Kalzit speziell haben sie gefunden, daß seine Löslichlzeit in Wasser selbst bei konstantem Kohlensäuregehalt bei einer Temperatursteigerung bis 350 Grad und bei hohem Druck nicht zunimmt (S. 368 und 370).

Ebenso wie den vgleichen hydrostatischen Druck « hat man auch die Wirkung »ungleichförmiger Pressung oder Streßpressung « ([91], S. 119 und 125) als Ursache für die Lösung an den Druckstellen der Gerölle angenommen.

WAGNER ([89], S. 126) nimmt für die Eindrücke eine Entstehung analog der der Stylolithen und Drucksuturen an; er beruft sich also auch für jene auf die Gültigkeit des von RIEcke (67) aufgestellten thermodynamischen Satzes von der Erniedrigung des Schmelzpunktes durch Einwirkung von einseitigem Zug oder Druck auf die feste Phase eines Stoffes, der mit seiner flüssigen Phase in Berührung ist. Auch SorBy hatte sicherlich schon 1863 ([37], S. 805) das gleiche im Sinne. Diese Depression des Schmelzpunktes ist unabhängig davon, ob die betreffende Substanz ihr Volumen beim Schmelzen vergrößert oder verkleinert ([75], S. 37).

Nach Becke ([75], S. 38), RIECKE ([88], S. 104) und anderen soll jener Satz im wesentlichen auch gelten sfiur ein System, das aus einem Kristall und seiner gesättigten lösung besteht $\ll$.

Eine Verallgemeinerung und Frweiterung seiner Anwendung auf geologische Prozesse erfuhren diese Erkenntnisse durch NIgGLr (91), JoHNsToN u. a. "Ganz allgemein erhöht ein Uberdruck auf die feste Phase ihre Löslichkeit, erniedrigt bzw. ihre Schmelztemperatur. Überall, wo der Streß lokal einen großen Betrag erreicht, findet Auflösung statt « ([91], S. 131).

Während aus den Arbeiten von RIEcke ([88], S. 103) klar hervorgeht, daß die Schmelzung an einem gepreßten Eisprisma gleichmäßig auf den freien Seitenflächen erfolgt, wurde von BECKE scharf unterschieden zwischen Stellen stärkerer Pressung und Stellen schwächerer Pressung an ein und demselben Körper. An ersteren findet demgemäß Auflösung; an letzteren dagegen Kristallisation. statt. Diese Wirksamkeit des RIDCKaschen Prinzips wird auch von SPEZIa ([104], S.13-14 des Sonderabdr.), allerdings nur in beschränlstem Maße, für die Entstehung der Verzahnung der Quarzkörnchen in grobkörnigen Sedimentquarziten für 
wahrscheinlich gehalten. Werden Körper also an einem begrenzten Teil ihrer Oberfläche einem Drucke ausgesetzt, so muß sich hier eine Vertiefung, ganz ähnlich den Eindrücken, ausbilden. Der entgegengesetzte Fall, daß an der Druckstelle gerade keine Auflösung stattfindet, dürfte niemals eintreten. Es können also alle die Eindrücke in Geröllen, die noch völlig erhaltene Berührungskegel aufweisen, und weiterhin auch alle diejenigen, in denen nur noch Reste von solchen vorhanden sind, unmöglich durch Auflösung infolge von Pressung erklärt werden.

Wie schon früher betont wurde, kann die Entstehung von Berïhrungskegeln beim Versuch und in der Natur nur durch die Tatsache gedeutet werden, daß sich an den Berïhrungsstellen kein Lösungsmittel befunden haben konnte, oder daß zum mindesten die Erneuerung der Flüssigkeit an diesen Stellen stark behindert war. PockELs hatte schon 1906 ([78], S. 667) den gleichen Einwand in einer Kritik theoretischer Arbeiten von PavLOW (Zeitschr. f. Krist. 40, 1905 und 42, 1906) erhoben gegen die Anwendung des thermodynamischen Potentials auf den Vorgang der Schmelzung und Auflösung durch einseitigen Druck. «Die gepreßten Flächen können aus mechanischen Gründen gar nicht mit der Lösung in Berührung stehen und folglich auch nicht sich auflösen. "

Wenn dieser Einwand auch für vollkommen sich berührende Flächen ohne weiteres als selbstverständlich zu betrachten ist, so kann doch für alle anderen Fälle die Möglichkeit einer Auflösung nicht geleugnet werden. Im übrigen ist PockwLs auch durch die Ausführungen NIGGLIs ([91], S. 125 u. f.) widerlegt worden. Jene Möglichkeit muß auch für die Berührungsstellen an den Gerölloberflächen als vorhanden angesehen werden, zumal an einigen Eindrücken aus dem Heidelberger Diluvium auf den Berührungskegeln deutliche Anzeichen von Auflösung zu erkennen sind (vgl. Fig. 3 und 5 der Tafel). Nur ist die Auflösung um die Berührungsstellen herum in bedeutend stärkerem Maße, d. h. viel schneller erfolgt als an ihnen selbst. Es muB daher auch hieraus gefolgert werden, daß nicht die Auflösung, wohl aber der andere Faktor, nämlich der löslichkeitssteigernde Druck, gefehlt hat.

Ganz unhaltbar ist nun auch die Annahme, daß sich gleichzeitig an dem gedrückten Geröll mit der Auflösung an den Berührungsstellen die gelöste Substanz aus übersättigter Lösung an den nicht gepreßten Teilen desselben Gerölls wieder in Form des kristallinen Utberzuges ausgeschieden hätte. Denn die Gleichzeitigkeit von Auflösung und Ausscheidung ist wenigstens für die N'agelfluhgerölle durch die Tatsache des Vorkommens von Kalzitabsatz in den Eindrücken selbst aufs deutlichste widerlegt. Auch ist nicht anzunehmen, daß die Auflösung in einer gesättigten Lösung stattgefunden hätte. Liegt doch viel eher die Vermutung nahe, daß es sich bei allen diesen Auflösungserscheinungen um absteigende Sickerwässer gehandelt hat, die, solange eine stetige Zufuhr 
vonWasser vorhanden war, stets untersättigt waren und überall auf ihrem Wege lösend wirkten. Hörte die Zufuhr gelegentlich oder für immer auf, so trat Verdunstung, Ubersättigung und Auskristallisation ein.

Aber aller dieser Auseinandersetzungen hätte es nicht bedurft. Denn durch die Tatsache des Vorhandenseins von Eindrücken in ungestörten diluvialen Geröllablagerungen ist allein schon die Unwirksamkeit des RIEckeschen Prinzips bei der Entstehung der Eindrücke als sicher zu betrachten. Ja, aus den Geröllen des Neckarschuttkegels geht sogar hervor, daß die Ausscheidung der dünnen Kalzithaut vor der endgültigen Ausgestaltung der Eindrücke sich vollzogen hatte. Die an der Stelle des Eindrucks lösende Wirkung des Wassers hat am Rande die Kalzitschicht sowohl unterhöhlt als auch von außen her angefressen (Fig. 5 der Tafel). Diese Tatsache mag vielleicht mit einem ehemals größeren Kalkgehalt der iiberlagernden Sand- und Lehmdecke oder mit großen Schwankungen in der Zuführung von Sickerwasser zusammenhängen.

Wir können aber auch an einigen anderen Beispielen erkennen, daß Auflösung nicht vom Druck abhängig zu sein braucht. So hat RoLuIER ([73], S. 214) einen Fall aus obermiozäner Juranagelfluh beschrieben, wo sich an vielen Geröllen die merkwürdige Erscheinung zeigte, daß die Oberfläche der Gerölle außerhalb der Vertiefungen der Eindrücke stärker durch das Lösungsmittel angegriffen worden war als die Eindrücke selbst. Er führt das auf eine stärkere Bewegung des Grundwassers (z. B. in Hochwasserperioden) zurück, wwährend die Eindrücke selbst nur dureh Sickerwasser in relativ trockneren Perioden entstanden sein mögen «.

Ein von W. Salomon und ein von mir in der Kiesgrube SW. von Eppelheim bei Heidelberg gesammeltes Geröll zejgen sehr deutlich, daß die Auflösung sich je nach der Flüssigkeitsmenge auch über einen großen Teil der Gerölloberfläche erstrecken kann, wobei aber stets die Berührungsstellen der Nachbargerölle als schöne Kegel erhalten geblieben sind (vgl. Fig. 4 der Tafel).

Ferner möchte ich nur noch auf die sogenannten »Rillensteine (93) hinweisen, bei deren oberflächlicher Auflösung ein Druck niemals wirksam gewesen ist.

\section{Auflösungshypothese.}

Aus der bisherigen Erörterung der einzelnen Hypothesen geht unzweideutig hervor, daß sowohl an Kieselsäure- wie an Kalksteingeröllen nur die rein chemische Auflösung tätig gewesen sein kann. Es verbleibt uns nunmehr die Aufgabe, die für die Lösungshypothese angeführten Argumente nach den bisher gewonnenen Erkenntnissen kritisch zu beleuchten, und daneben aber auch alle an den Eindrücken jemals beobachteten Erscheinungen vom Standpunkte dieser Anschauung aus zu erklären. 
Einen zwingenden Beweis für die stattgefundene Auflösung hatte man bisher nur für die Kalksteingerölle auffinden können.

Nach den Untersuchungen von SorBy und Hem entspricht das sich häufig in Eindrücken vorfindende tonige, sandig-tonige oder eisenschiissige Zwischenhäutchen dem unlöslichen Bestandteile des Gesteins. Nach Herms Messungen stimmen auch die Mengen des Rückstandes und die des unlöslichen Teiles der entfernten Gesteinsmasse genau miteinander überein.

Die Gründe, die READE (70) für die Auflösung an Quarziten als Beweise ansieht, scheinen mir nicht überzeugend zu sein. Das Fehlen von Sprüngen ist ebensowenig ein Beweis für die Auflösung, wie das Vorhandensein von Sprüngen als ein Anzeichen für die Wirksamkeit des Druckes bei der Entstehung der Eindrücke angenommen werden kann. Das Innere der meisten Eindrücke sei lichtgrau und die Purpurfarbe sei hinweggeführt. Die einzelnen Körner der echten Quarzite sähen an der Oberfläche der Eindrücke wie abgeschnitten aus. Beide Argumente schließen weder die mechanische noch die chemische Wirkung eines Druckes aus.

Ferner hat man meistens das Vorhandensein der Kieselsäure- bzw. Kalzitausscheidungen auf den Geröllen als ein Zeichen dafür angesehen, $\mathrm{da} B$ an den Beruihrungsstellen das Gestein vorher gelöst worden sei. Wir haben jedoch an dem Beispiel der jungdiluvialen Schotter bei Heidelberg gesehen, daß diese Ausscheidung durchaus nicht eine Folge eines Auflösungsvorganges an denselben Geröllen zu sein braucht, an denen sie sich bildete, sondern daß sie genetisch älter sein kann als die Auflösung an den Berührungsstellen.

In den von READE geschilderten Fällen läßt sich ebenfalls die Altersfolge erkennen. Er beobachtete, daß die Sprünge in den Geröllen zum Teil mit Kieselsäure wieder ausgefüllt sind, die Ausfülllung demnach jünger als die Sprünge ist, die an und für sich schon jünger sind als die Eindrücke.

Aus dem Buntsandstein kann ich leider nicht über eine unzweideutige Beobachtung der Altersfolge von Ausscheidung und Zerquetschung berichten. Wohl ist mir ein Fall von Barytkristallisation in einer Geröllkluft aus der Gegend von Zabern bekannt, aber nicht von Kieselsäure. Wahrscheinlich beruht aber die Verfestigung des Konglomerates, das Festsitzen der Gerölle ineinander, auf nachträglicher Auskristallisation von Kieselsäure in den Eindrücken.

Für ein Produkt dieses Ausscheidungsvorganges haben READE (70) und ToRNQUIST ([80], S.213 und 218) die grobkristalline Quarzausfüllung zahlreicher Eindrücke in Sedimentquarzitgeröllen aufgefaßt. Es läßt sich jedoch leicht feststellen, daß beide hier einer Täuschung zum Opfer gefallen sind. Quarzausscheidungen auf den Gangquarzit- und Sedimentquarzitgeröllen sind weit verbreitet und auch des öfteren in der Literatur erwähnt worden. Aber es ist doch ein wesentlicher Unterschied zwischen 
dem kristallinen Uberzug auf einem Gangquarzitgeröll und dem auf einem Sedimentquarzitgeröll vorhanden. Während er sich nämlich auf dem ersteren als eine einzige, nur von kleinen Löchern, in denen sich Sandkörnchen befunden hatten, unterbrochene, in großen Flächen spiegelnde Schicht, als ein Kieselschmelz, darstellt, ist er auf den Sedimentquarziten nur in feinen Schüppchen gleichwie ein leichter Flimmer ausgebreitet. Ja, er ist häufig sogar nur auf den sie durchziehenden Quarzadern zur Ausbildung gekommen. Diese Tatsache erklärt sich leicht daher, daß auf den Geröllen aus reinem Quarz die Ausscheidung überall erfolgen konnte, während an den Sedimentquarziten nur die an der Oberfläche erscheinenden reinen Quarzkörnchen für das Ansetzen von neuen Kristallflächen geeignet sind, und die mehr oder minder verunreinigten Körnchen sowie das oft eisenschüssige Bindemittel davon verschont bleiben. Es ist der Unterschied also die Folge der verschieden großen Oberfläche, die der Lösung geboten wird. An den winzigen Körnchen der Sedimentquarzite können sich demnach nur winzige Kristallflächen ansetzen. Der Unterschied wird auch sofort deutlich, wenn man die Fazettierung eines grobkörnigen Sedimentquarzitgerölls und eines feinkörnigen miteinander vergleicht. Die des ersteren ist stets stärker, selbst kleine isolierte Kristallindividuen können sich größeren Körnern aufsetzen. Man kann daher mit Sicherheit annehmen, daß der kristalline Überzug, wenn er sich in den Eindrücken der Sedimentquarzitgerölle gebildet hätte, genau das gleiche Aussehen haben müßte wie auf den übrigen Teilen der Gerölloberfläche. Aus welchem Grunde sollte sich dort allein eine Ausscheidung von grobkristallinem Quarz bilden können, die Löcher von 3-4 mm Tiefe völlig ausgefüllt und sogar deren Rand überragt hätte? Die Beantwortung ist unmöglich, und bei näherer Untersuchung ergibt sich, daß die Ausfüllungsmasse nichts weiter ist als Reste von Gangquarzitgeröllen, die beim Herauslösen des Gerölls aus dem Verbande des Konglomerates abgebrochen sind. Durch Abschlagen von noch anhaftenden Gangquarzitgeröllen erzielt man recht leicht diese Erscheinung. Die Füllungsmasse hat demgemäß auch keineswegs die glashelle Farbe wie die kristallinen Uberzuige der fazettierten Gerölle, sondern ist meist milchweiß wie die Gangquarzitgerölle selbst, gelegentlich sind sie aber auch gelblich gefärbt, und als Seltenheit kommt auch einmal ein Eindruck vor, der durch das Bruchstück eines eingedrungenen Sedimentquarzitgerölls ausgefüllt ist. Eine kristalline Ausfüllung der Eindrücke in Gangquarzitgeröllen, wo sie sich doch gerade in deutlichster Weise zeigen muißte, wenn sie auf Kristallisation zurückzuführen wäre, habe ich nie gefunden. Die grobkristalline Ausfüllung ist dagegen sehr schön an dem fruiher erwähnten Kieselschiefergeröll aus dem Schwarzwalde zu beobachten, wo überdies genau wie auf den von ToRnQUist ([80], Tafel 7, Fig. 1 und 2) abgebildeten Quarzitgeröllen jegliches Anzeichen von Fazettierung fehlt.

Es könnte merkwïrdig erscheinen, daß in den Buntsandsteinkon- 
glomeraten diese Ausfüllungen fast ausschließlich nur aus Quarz bestehen. Das erhellt aber sofort aus dem Umstande, daß weitaus die größte Anzahl von Eindrücken sich in den Sedimentquarzitgeröllen vorfindet. Denn erstens sind die Gangquarzitgerölle in der Uberzahl und zweitens scheint die feinkörnige Beschaffenheit der Sedimentquarzite die Auflösung des Quarzes gegenüber den grobkörnigen Gangquarziten zu begünstigen. Möglicherweise spielt auch der Größenunterschied zwischen beiden Geröllarten dabei eine gewisse Rolle. Auf diese Fragen komme ich jedoch später noch zu sprechen (siehe S. 219 u. f.). Einige Zahlenbeispiele aus dem Hauptkonglomerat der Vogesen mögen seine Zusammensetzung und die Häufigkeit von Eindrücken an den Geröllen mit mehr als $8 \mathrm{~mm}$ größtem Durchmesser sowie gleichzeitig die Größe ihrer mittleren Durchmesser darlegen.

\begin{tabular}{|c|c|c|c|c|c|c|}
\hline \multirow{2}{*}{ Örtlichkeit } & \multirow{2}{*}{ 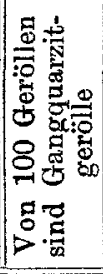 } & \multirow{2}{*}{ 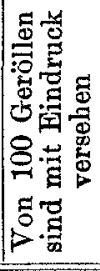 } & \multicolumn{2}{|c|}{$\begin{array}{l}\text { Von } 100 \text { Geröllen } \\
\text { d. betr. Gesteins- } \\
\text { art enthalten } \\
\text { Eindrücke }\end{array}$} & \multicolumn{2}{|c|}{$\begin{array}{l}\text { Mittlerer } \\
\text { Durchmesse } \\
\text { der Gerölle } \\
\text { in } \mathrm{mm}\end{array}$} \\
\hline & & & 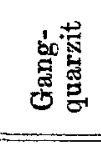 & 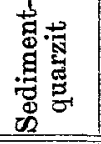 & 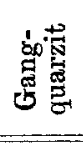 & 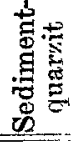 \\
\hline $\begin{array}{l}\text { 1. Le Cone bei La Chapelle südöstl. } \\
\text { Bruyères }\end{array}$ & 66,3 & 32 & 23,5 & 50 & 17,5 & 25,2 \\
\hline 2. La HauteVerrière südI. Bruyères & 72,6 & 18 & 18,9 & 15,4 & 20,8 & 27,2 \\
\hline $\begin{array}{l}\text { 3. Mont d'Ormont bei Rehaupal u. } \\
\text { Tendon }\end{array}$ & 70 & 10 & 0 & 33 & 18,6 & 22,6 \\
\hline 4. Urimenil-Uzemain & 65 & 6,6 & 0 & 18,8 & 20,2 & 28,1 \\
\hline 5. Relanges südwestl. Epinal & 69 & 2 & 0 & 6,6 & 13,3 & 28,6 \\
\hline 6. Thunimont & 66,6 & 28 & 28,3 & 27,3 & 22,5 & 28,2 \\
\hline 7. Nördl. Remiremont & 57,3 & 10 & 3,6 & 19,5 & 21,3 & 31,1 \\
\hline 8. Belverne & 55 & 5 & 0 & 11,4 & 22,5 & 25.6 \\
\hline 9. Aue bei $\mathrm{Ma}$ & 52,3 & 10,2 & 0 & 21,4 & 20 & 22,7 \\
\hline 10. Gebweiler-Bergholz-Zell & 60,3 & 18 & 12,2 & 26,9 & 19,9 & 24,8 \\
\hline 11. St. Odilien bei Barr & 75,5 & 24 & 20 & 37,5 & 18,8 & 20,5 \\
\hline 12. Rabenfels westl. Mutzig & 59,8 & 20 & 13,8 & 30,8 & 20,4 & 21,3 \\
\hline 13. Bertrichamp östl. Baccarat & 75,5 & 3 & 1,4 & 8 & 22,9 & 25 \\
\hline
\end{tabular}

Aus der Tabelle geht also hervor, daß erstens die Gangquarzitgerölle in bedeutend größerer Zahl an der Zusammensetzung des Konglomerates beteiligt sind und daß zweitens ein ziemlich großer Prozentsatz der Gerölle mit Eindrücken versehen ist, wobei die Sedimentquarzitgerölle wesentlich häufiger Eindrücke aufweisen als die Gangquarzitgerölle. Nur an den beiden Punkten 2 und 6 ergaben sich für die Gangquarzite ein wenig größere Werte als für die Sedimentquarzite. Ferner sind die mittleren Durchmesser der ersteren stets kleiner als die der letztgenannten.

Noch viel offensichtlicher geht aus den Eindrücken in Nagelfluhgeröllen hervor, daß die öfter in ihnen befindliche Ausfüllungsmasse 
nicht in ihnen selbst entstanden ist, sondern nur aus Teilen ehemals im Eindruck haftender Gerölle besteht. Es sind dabei naturgemäß alle Arten von Gesteinen vertreten, die in den gemischten Konglomeraten vorhanden sind.

Die Ursache für das Festsitzen von Geröllen in den Eindrücken ist in der Verfestigung der Zwischenhaut, nämlich des Auflösungsrückstandes, vielleicht aber auch in der Auskristallisation von Kieselsäure zu suchen und bei den Kalkgeröllen zu einem großen Teile sicher in einer dünnen Schicht von neugebildetem Kalzit, die sich zwischen Geröll und Eindruckswand ausgeschieden hat. Man erkennt die Kalzitausscheidung sowohl in freiliegenden Eindrücken als auch in solchen, aus denen man erst nachträglich das eingedrungene Geröll entfernt hat. Sie ïberzieht durchaus nicht immer in gleichmäßig dünner Schicht den ganzen Eindruck, sondern findet sich oft nur in kleineren Fetzen, meistens die größeren Vertiefungen in ihm ausfüllend, oder nur als Verkleidung der einen Wand. Der eindringende Geröllteil bat demnach nicht durchweg die Vertiefung völlig auszufüllen vermocht.

Die Tatsache, daß fast ausschließlich an den Berührungsstellen der Gerölle untereinander bzw. der Sandkörner mit den Geröllen die Auflösung stattgefunden haben muß, erklären die Anhänger der rein chemischen Lösung durch die Kapillarität, durch die das Lösungsmittel an jenen Stellen sich länger hielt als an der übrigen Oberfläche der Gerölle. Diese Annahme wird uns aufgezwungen durch die negativen Ergebnisse aller Lösungsversuche bei ständiger ausgiebiger Benetzung der gesamten Gerölloberfläche und durch die Möglichkeit, allein dureh Einwirkung des Lösungs mittels auf die Kontaktstellen, naturgetreue Nachahmungen der Eindrücke auf experimentellem Wege zu erzielen. Außerdem scheint mir durch alle anderen Annahmen, abgesehen von den rein mechanischen, keine Erklärung für den meist verhältnismäßig scharfen Rand der Eindrücke gegeben werden zu können und vor allem auch nicht für einige von mir beobachtete Fälle, wo eine deutliche Vertiefung und korrodierte Oberfläche zwischen zwei scharfen Eindrücken wahrzunehmen ist. Da, wo sich noch die beiden kleinen, wenig gerundeten Gerölle in den Vertiefungen befanden, die einige Millimeter auseinander liegen, während sich die Gerölle oben berïhrten, war leicht zu erkennen, daB hier die beiden kapillar festgehaltenen Flüssigkeitsmassen ineinandergeflossen waren.

Die Flüssigkeitsmenge muß lange Zeit hindurch konstant gewesen sein, sonst hätten die scharfen Ränder nicht entstehen können. Zufuhr and Abfluß plus Verlust durch Verdunstung müssen sich während der Entstehungszeit der Eindriicke in engen Grenzen gleichgeblieben sein.

Dieser Satz läßt uns die Möglichkeit erkennen, den Beginn und das Ende der Entstehungszeit der Eindrücke näher zu bestimmen. 
Eine Regelung der Zufuhr konnte nur vorhanden sein unter einer einigermaßen starken Sedimentdecke, die durch ihre Wasseraufnahmefähigkeit imstande war, auf die jahreszeitlichen Schwankungen der Niederschlagsmengen ausgleichend zu wirken. Andererseits aber mußte auch ein genügend und gleichmäBig starker Wasserabfluß gewährleistet sein, der eine völlige Erfüllung der Konglomeratmassen mit Wasser verhinderte. Eine zu geringe Mächtigkeit der Deckschicht vermag durch die Schwankungen der durchsickernden Wassermengen nur einen Wechsel von Zeiten der Auflösung mit solchen der Ausscheidung herbeizuführen (vgl. hierzu S. 214 und Fig. 3, 4 und 5 der Tafel).

Gelangten die Konglomerate durch Uberlagerung oder Absenkung in größere Tiefe, dann mußte der Abfluß aufhören; die ganze Ablagerung füllte sich verhältnismäßig rasch mit Wasser, dessen Zirkulation dadurch mehr und mehr aufgehoben wurde und dessen Sättigungsgrad bis zur Konzentration zunahm. Die Eintiefung der Eindrïcke war mit Beginn dieser Periode im wesentlichen beendet und hatte durch die Auflösung an den benetzten Stellen vorübergehend zu einer partiellen Lockerung in den Geröllschichten geführt, wodurch es einzelnen günstig liegenden Geröllen ermöglicht wurde, durch ihr eigenes Gewicht in die Vertiefung eines tiefer liegenden Gerölls nachzudringen und so zur Entstehung tieferer Eindrücke Anlaß zu geben. Traten dann Hebungen ein mit ihrem Gefolge von Verwerfungen, Überschiebungen und Erosion, so war die Möglichkeit des Abfließens der Lösung bzw. der Einengung der Lösung durch Verdunstung des Wassers gegeben und führte zur Ausscheidung der gelösten Substanz. Möglicherweise hat dabei auch die Mitwirkung von Mineralisatoren, die auf dem Wege der Verwerfungen in die Konglomerate gelangten, bei der Ausfällung von Kieselsäure eine große Rolle oder gar die Hauptrolle gespiett ([80], S. 218).

Während dieses Vorganges ging gleichzeitig die Entstehung der Druckerscheinungen, wie Zerquetschung der Gerölle und Riefung der Eindrücke sowie der Gerölloberflächen, vor sich. Die Riefung kann erst nach der Verfestigung des Bindemittels eingetreten sein, denn gerade auf den Kalzitausscheidungen in den Eindrücken zeigt sie sich am schönsten. Wahrscheinlich erfolgte auch jetzt erst durch den Anstoß der tektonischen Bewegungen die Lösung der Spannung in den Konglomeraten und Sanden, so daß die dem Druck der jüngeren Sedimente und dem überwiegenden lateralen Drucke ausgesetzten Geröllmassen diesem in ihren einzelnen Komponenten naehgeben und so die einen Gerölle in die Vertiefungen anliegender Gerölle völlig eindringen konnten. Sie paßten dabei durchaus nicht immer genau ineinander, wie in der Literatur geschildert wird, sondern es blieben sowohl an den Seiten sowie in der Tiefe des Eindrucks vielfach kleine Zwischenräume frei, die sich mit Kalzit ausfüllten.

Daß die Höhlung des Eindrucks meist größer sein muß als der in sie eindringende Geröllteil, ergibt sich aus der einfachen Tatsache, daß 
der Umfang der von der Flüssigkeit benetzten Fläche auf dem flacher gekrümmten Geröll größer ist als auf dem stärker gekrümmten Geröll (vgl. Textfig. 2, wo $r<R$, und Versuch 3 auf S. 225).

Es ergibt sich daraus allein schon die Folgerung, daß stets nur das Geröll mit dem kleineren Krümmungsradius an der Berührungs- oder besser Benetzungsstelle in das mit dem größeren eindringen kann. Das Gegenteil ist schlechterdings in demselben Ausmaße unmöglich, selbst wenn die Löslichkeit des ersteren weit die des letzteren übertreffen sollte.

Je nachdem die Auflösung an dem Geröll mit dem kleineren Krümmungsradius mehr oder weniger gleichmäßig von der Oberfläche aus in die Tiefe fortschreitet, wird sich eine mehr oder weniger große Änderung der Krümmung vollziehen; sie wird anfangs nur sehr gering sein

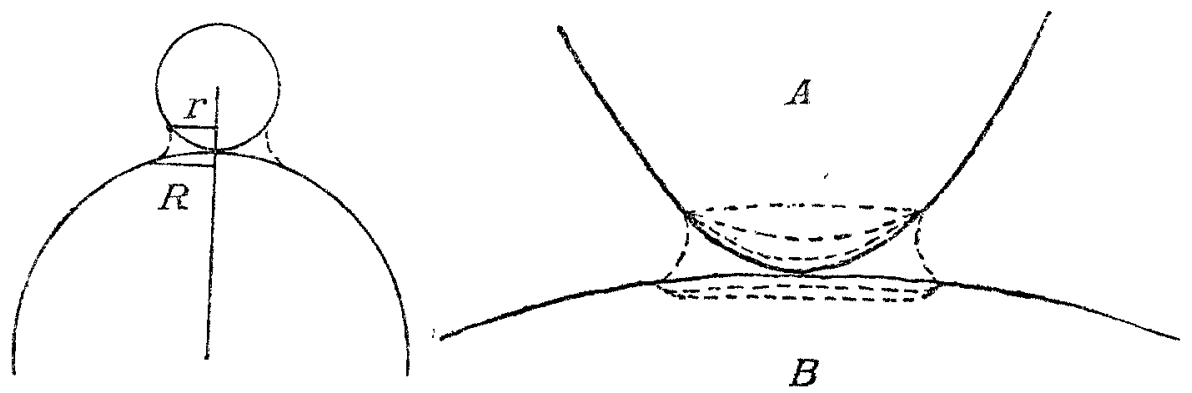

Fïg. 2.

Fig. 3.

und schließlich bei andauernder Auflösung sehr stark zunehmen (vgl. Textfig. 3). Es wird sich aber in diesem Falle stets nur eine Abflachung bei dem Geröll mit dem kleineren Krümmungsradius erzielen lassen, in die gegebenenfalls das schwächer gekrümmte Geröll hineinragen würde, wenn es schwerer löslich ist und der in ihm befindliche Eindruck noch eine konvexe Krümmung beibehalten hat (vgl. Geröll $B$ in Textfig. 3). Trotzdem dürfte aber dieses Eindringen des flacheren Gerölls in das ehemals spitzere Geröll äußerlich nur als ein Eindringen des letzteren in das erstere zu erkennen sein, denn der Durchmesser der Höhlung in diesem muß ja, wie wir oben gesehen haben, stets größer sein als der des spitzeren Gerölls am Rande seiner Benetzungsfläche. Ferner ist dabei auch zu bedenken, daß sich bei einigermaßen gleicher Löslichkeit beider Gerölle die konvexe Krümmung des flacheren Gerölls weit schneller in eine konkave Krümmung verwandeln wird, ehe sich noch an dem spitzeren eine wesentliche Ânderung des Krümmungsradius durch die Auflösung vollzogen hätte.

Es ist nun aber nicht die Tatsache der Verschiedenartigkeit der Krümmungsradien allein als die Ursache des Eindringens von einem Geröll in den Eindruck des anderen anzusehen, wie sich aus folgenden Betrachtungen und Überlegungen ergibt. Völlig ebene und gleichmäßig tiefe Eindrücke in einer ebenen Fläche eines größeren Gerölls lassen 
vermuten, $\mathrm{da} B$ diese Eindrücke in Verbindung mit einer ebenfalls ebenen Fläche eines kleineren Nachbargerölls entstanden sind. Es ist also in diesen Fällen trotz gleicher Krümmungsradien ein Eindringen des einen Gerölls in das andere, und zwar des kleineren in das größere, erfolgt, wie es anders ja auch gar nicht möglich ist (vgl. T'extfig. 4).

Entscheidend ist also demnach nicht der Unterschied in der Größe der Krümmungsradien, sondern allein der Unterschied in der Größe der Durchmesser des Randes der sich gegenüberliegenden Benetzungsflächen zweier Gerölle. Der Löslichkeitsunterschied spielt dabei gar keine Rolle. Ein Eindringen würde also auch erzielt werden, wenn das Material des $k$ eineren oder des stärker gekrümmten Gerölls stärkerlöslich wäre als das des größeren oder schwächer gekrümmten Gerölls.

Die notwendige Folgerung daraus wäre die Vorstellung, daß sehr wohl ein Geröll, dessen

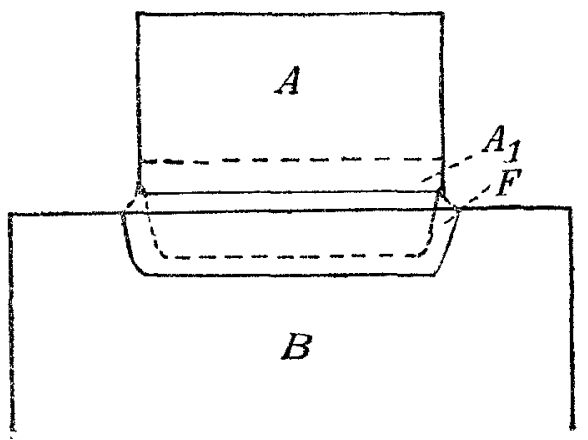

Fig. 4. $A$ und $B$ ursprüngliche Form der Geschiebe. $A_{1}$ (punkt. Um iß) ersteres nach starker Auflösung. F Flüssigkeit im Ein. druck in $B$. Durchmesser der Benetzungs-

fläche selbst mit fortschreitender Auflösung stets kleiner ist als der Durchmesser des Hohlraumes in dem anderen Geröll, dieses letztere vollständig durchbohren könnte, eine Erscheinung, die ganz dem Wachsen der Stylolithen, dem Durchbohrtwerden großer Stylolithen durch kleinere und dem Durchbohren der Stylolithen durch Versteinerungen analog wäre. Eine bestimmte Lagerung der Gerölle, die den Zutritt von Flüssigkeit gestattet, scheint dafür allerdings erforderlich zu sein.

Die von Köchlis-Sohlumberater (17) und AlB. HeIm (92) vertretene Ansicht, daß das Eindringen des Gerölls mit kleinerem Krümmungsradius in das mit dem größeren auf die nur von dem ersteren auf der Oberfläche des letzteren hervorgerufene Desdggregation zuriickzufïhren wäre, habe ich oben schon (S. 207-211) in anderem Zusammenhange als abzulehnen bezeichnet.

Wie wir aus den vorhergehenden Betrachtungen ersehen, ist es durchaus nicht notwendig, für die Erscheinung des Ineinandereindringens der Gerölle einen auf der Größe der betreffenden Krümmungsradien beruhenden Löslichkeitsunterschied zweier Gerölle verantwortlich zu machen. Die Tatsachen der Adhäsionserscheinungen genügen allein zu ihrer Erklärung. Es darf also umgekehrt keineswegs aus dem Vorhandensein des Eindringens eines Gerölls in den Eindruck eines anderen géfolgert werden, daß die Löslichkeit des eingedrungenen Geröllteiles geringer sein mijßte als die des anderen Gerölls. 
Wenn nun aber trotzdem in der Natur zahlreiche Fälle zu beobachten sind, wo es sich unzweifelhaft feststellen läßt, da $b$ an dem eingedrungenen Geröll gar keine oder wesentlich schwächere Auflösung stattgefunden hat als jene, die sich in dem anliegenden Geröll in der Größe des Eindrucks erkennen läßt, so ist die Frage nach der Ursache dieses Unterschiedes scharf von der oben behandelten Frage zu trennen. Sie sei Gegenstand der folgenden Untersuchungen.

SoRBY ([37], S. 806) bezeichnete es als Tatsache, daß in der Regel von zwei sich berührenden Geröllen nur das eine gelöst wurde, und führte den Löslichkeitsunterschied auf verschiedenartige Struktur der Gerölle zurück, wobei auch ihre Form einen gewissen Einfluß gehabt haben könnte (vgl. auch S. 192 dieser Arbeit). Auch DaUbRÉE ([53], S. 293) scheint an etwas Ähnliches gedacht zu haben, als er schrieb, daß die sEindrücke im allgemeinen durch den größten Krïmmungsradius bestimmt « wïrden, wofür er aber noch keinen Grund erkennen könne. 1857 (24) spricht er jedoch nur davon, daß bei den Lösungsversuchen mit Kugeln von verschiedener Größe und von verschiedenen Kalkarten immer eine derselben vorzugsweise angegriffen wurde. HEm hat ebenfalls beträchtliche Unterschiede des Ausmaßes der Auflösung erkannt, aber daneben doch gelegentlich deutliche Anzeichen von Auflösung an den eindringenden Geröllen festgestellt, die er damit erklärt, daß sich bei fortgeschrittener Eintiefung des Eindrucks in dem anderen Geröll die Unterschiede in den Krümmungsradien der Berührungsflächen ausgeglichen hätten und daB nunmehr auch beide Gerölle in gleichem Maße hätten angegriffen werden können ([92], S. 61).

ToRnquists und meine eigenen Beobachtungen scheinen mir aber keine Verallgemeinerung der obengenannten Erscheinung zuzulassen, ja, sie stehen sogar teilweise in einem gewissen Gegensatz zu den bisherigen Deutungsversuchen.

An den Geröllen des oligozänen Küstenkonglomerates des Letzenberges im Elsaß fand Tonnquist ([80], S. 216), daß die worstehende Ecke des einen Gerölls manchmal mehr gelöst wird als Teile der Fläche eines benachbarten Gerölls, gegen welche sie gelegen ist, während manchmal das Umgekehrte der Fall ist. " Die Untersuchung der wenigen mir zur Verfügung stehenden Fälle, wo ich ein kleines in dem Eindruck eines größeren steckendes Geröll herauslösen und die untere Fläche betrachten konnte, zeigte, daß ebensooft an ihr eine starke Auflösung als ein Fehlen derselben festgestellt werden konnte. Als ein Beispiel sei in nebenstehender Textfig. 5 ein Schnitt durch den Eindruck eines flachen Gerölls $B$ und durch das darin befindliche Geröll $A$ wiedergegeben. Hier ist das kleine Geröll $A$, dessen vermutliche ursprïngliche Form die punktierte Linie andeutet, viel stärker aufgelöst als das große Geröll $B$, trotzdem $A$ den kleineren Krümmungsradius hatte. Kann man in diesem Falle mit Herm annehmen, daß sich zuerst in $B$ ein Eindruck gebildet hätte, dessen konkave Krümmung mit der Zeit völlig der konvexen des 
eindringenden Gerölls gleich geworden wäre, und daß nun erst die Auflösung des letzteren, also hier des Geröls A, eingesetzt hätte? Die Form des Eindrucks in $B$ widerspricht dem völlig, da er in keiner Weise mit der zu mutmaßenden ursprünglichen Form des Gerölls $A$ übereinstimmt. Es ist anzunehmen, daß die Auflösung von $A$ gleichzeitig mit der von $B$ begonnen haben wird.

In der Geröllform kann also der Löslichkeitsunterschied, wie er ineinigen anderen Fällen deutlich zu erkennen war, nicht begründet

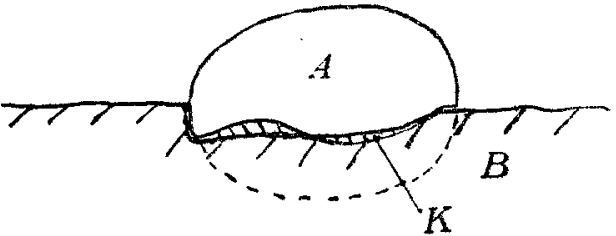

Fig. 5 (5fach linear vergrößert). $K$ Kalzit. sein, da sich ja einmal das schwächer gekrümmte Geröll und ein anderes $\mathrm{Mal}$ das stärker gekrümmte Geröll als weniger von der Auflösung angegriffen erweist.

Uberdies ist auch in dem Auftreten von stylolithischen oder suturähnlichen Verzahnungen, die von RothPLETz, FrüH, SchaAd und Herk beschrieben worden sind, ein Beweis für das Vorkommen von Auflösung an beiden Geröllen zu erblicken.

Im allgemeinen mag gesagt werden, daß diese wohl häufiger vorkommen wird, als man anzunehmen scheint, nur daßs sie wesentlich schwieriger zu beobachten sein wird. Denn erstens tritt sie an stark gekrümmten Geröllen, wenn die Auflösung nämlich einen größeren Teil der Gerölloberfläche mehr konzentrisch angreift und noch nicht weit fortgeschritten ist, nicht mehr augenfällig in die Erscheinung ( $\nabla g l$. Geröll $A$ der Textfig. 3, Geröll $A-A_{1}$ in Textfìg. 4, Geröll $A_{1}$ in Textfig. 8, Fig. 2 und Fig. 4 der Tafel), und zweitens ist die Beobachtung überhaupt nur dann einwandfrei möglich, wenn beide Gerölle noch ineinanderhaftend angetroffen werden. Sind nämlich die einzelnen Gerölle bereits aus dem Verbande gelöst, so dürfte es schwer sein zu entscheiden, ob ein Eindruck oder vielmehr eine Abplattung eines Gerölls $A$ (siehe Textfig. 6) in Berührung mit einem flacheren Geröll $B$

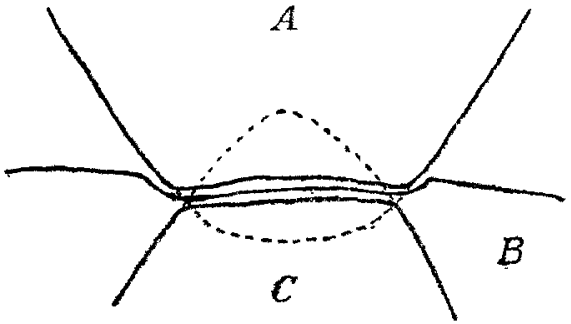

Fig. 6. oder mit einem gekrümmteren Geröll $C$ entstanden ist, ob also die abgeplattete Stelle in den größeren Eindruck eines flacheren Gerölls hineinragte, oder ob umgekehrt ein spitzeres Nachbargeröll diese Abplattung verursachte.

Für die Erklärung der Erscheinung einer versehiedenen Löslichkeit zweier Gerölle kann nun nach Ablehnung des Einflusses des Form- 
anterschiedes nur noch der Iöslichkeitsunterschied in Frage kommen, der auf vielleicht nur geringen strukturellen oder petrographischen Gesteinsunterschieden oder auf einer verschiedenen Glättung der fraglichen Gerölle beruhen mag. Was den letzteren Punkt anbetrifft, so könnte ja angenommen werden, daß die kleineren Gerölle etwa auf einem längeren Transportwege eine stärkere Abschleifung und damit eine größere Glättung ihrer Oberfläche erfahren hätten, und daß daraus vielleicht eine Bevorzugung der kleineren Gerölle in dem Widerstande gegen das Lösungsmittel herzuleiten sei.

Um diese Frage zu entscheiden und um die weiter oben gefundenen Wrirgebnisse der Untersuchung über den Einfluß des Formunterschiedes auf das Ineinandereindringen und auf die Löslichkeit der Gerölle auch durch das Experiment zu erweisen, habe ich eine weitere Reihe von Versuchen angestellt.

\section{Versuch 1.}

Zwei polierte, aus dem gleichen Gesteinsstiuck gefertigte Kugeln von einem Durchmesser von $29 \mathrm{~mm}$ bzw. $26 \mathrm{~mm}$ wurden auf einer ebenen Sandschicht nebeneinander gelegt, so daß sie sich beruihrten. Wegen der verschiedenen Größe lagen die Kugeln etwas gegeneinander geneigt, d. h. der Mittelpunkt der größeren Kugel lag etwas über dem Berührungspunkte. Alle 12-15 Sekunden fiel ein Tropfen stark verdünnter Salzsäure aus $0,5 \mathrm{~cm}$ Höhe auf die Berührungsstelle herab. Nach 6 Stunden zeigten sich an beiden Kugeln die kraterförmigen Vertiefungen mit je einem schönen Berührungskegel. Die Abflußrinne ist auf der thleineren Kugel, und auf ihr ist auch die Vertiefung ein wenig tiefer, sie äußert sich auf der großen mehr als Abplattung.

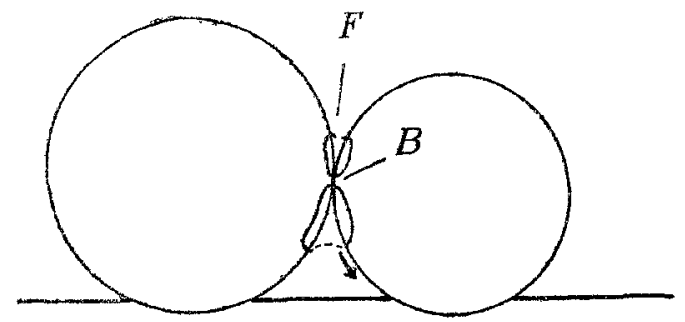

Fig. 7 (nat. Größe). B Berührungskegel. $F$ Flüssigkeit.

Bei Fortsetzung des Versuches hielt sich das Lösungsmittel nur noch an und unter den Berührungskegeln, die nach weiteren 6 Stunden so weit erniedrigt waren, daß sich keine Flüssigkeit mehr zwischen ihnen halten konnte. Ein typischer konkaver Eindruck wurde nicht erzielt, da sich die Kugeln nicht nähern konnten (vgl. Textfig. 7). Außerdem zeigten sich an der Auflagerungsfläche auf dem Sande sehr hübsche Eindrücke der einzelnen Sandkörner, und zwar häufig mit Berührungskegeln. Diese Eindrücke sind oft miteinander verschmolzen. 
Versuch 2.

Dieselben Kugeln wurden in die umgekehrte Lage gebracht, also die kleine etwas höher gelegt als die große. Es zeigten sich wiederum die Berïhrungskegel, die nach einiger Zeit verschwanden. Die Fliüssigkeit war diesmal an der größeren Kugel abgeflossen. Fin Eindringen fand nicht statt, da die Kugeln sich auch hier einander nicht nähern konnten.

Versuch 3.

Die große Kugel yon $29 \mathrm{~mm}$ und eine kleinere ebenfalls polierte Kugel von nur $11 \mathrm{~mm}$ Durchmesser wurden am Grunde eines Trichters șchräg aufeinander gelegt. Alle 60 Sekunden ließ ich einen Tropfen auf die kleinere auffallen. Es entstanden zwei Beriihrungskegel von je $1 \mathrm{~mm}$ Höhe. Die kleine Kugel war nur abgeplattet, die große vertieft. Die Flüssigkeit hielt sich nur noch an und unter den Berïhrungskegeln. Die kleine Kugel fiel schließlich von den Kegeln herunter. Diese lösten sich auf, und neue schwächere Beriihrungskegel entstanden an der neuen Berührungsstelle. Nach 3-4 Tagen schien die kleine Kugel bis zur Hälfte in die große eingedrungen (siehe Fig. 8), jedoch zeigte sich die eingedrungene Hälfte stark abgeplattet und uneben, während die Vertiefung in der größeren wie ein typischer Eindruck konkav gekrümmt war. Der Durch-

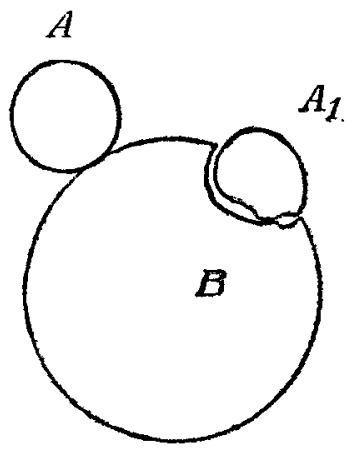

Fig. 8 (nat. Größe).

$A$ kleine Kugel vor, $A_{1}$ nach der Auflösung. messer dieses Eindruckes betrug $11 \mathrm{~mm}$, war also so groß wie der ursprüngliche Durchmesser der kleineren Kugel, während der der kleineren Kugel sich in manchen Richtungen auf $10 \mathrm{~mm}$ vermindert hatte.

\section{Versuch 4.}

Zwei gleich große Kugeln von $22 \mathrm{~mm}$ Durchmesser, aber aus zwei auch petrographisch etwas verschiedenen Gesteinsstücken von Muschelkalk wurden ebenso aufeinander gelegt. Die tieferliegende der beiden war poliert, während die obere eine matte Oberfläche hatte. Schon nach kurzer Zeit zeigte sich, daß an der Benetzungsfläche der ersteren die Politur verschwunden war, während an der letzteren eine Glättung eingetreten war. Die Unterschiede glichen sich also sehr schnell aus. Beide Eindrücke waren anscheinend gleich tief, und sie sowie die Berührungskegel hatten genau die gleichen Durchmesser. Die aufeinander aufliegenden Stellen der Berïhrungskegel zeigten unter dem Mikroskop bei beiden nicht die geringste Spur einer Auflösung. 


\section{Versuch 5 .}

Bei Fortsetzung des Versuches mit vertauschter Lagerung der $\mathrm{Ku}$ geln und unter Aufhebung der Annäherungsmöglichkeit ergaben sich nach Auflösung der Kegel an beiden Kugeln unebene Abplattungen, von denen die in der unteren Kugel etwas tiefer ist, was allein darauf zuriückzuführen sein dürfte, $\mathrm{daß}$ hier noch Flüssigkeit auftropfte, als die Entfernung der beiden Flächen zu groß geworden und die Kapillarität. nicht mehr wirksam war.

Ein Eindringen konnte auch nach einer Wiederannäherung nicht erzielt werden.

Als Ergebnisse dieser Versuche kann bezeichnet werden, da $\beta$ erst ein beträchtlicher Unterschied in der Größe der Radien ty pische Eindrücke mit Eindringen des kleineren Gerölls bewirkte und $\mathrm{da} B$ die Vertiefungen um so geringer ausfallen, je geringer der Größenunterschied ist, während Politur, Struktur und Lagerung der Gerölle keinen Einfluß, wenigstens bei dem angewandten Grade der Verdünnung, zu haben scheinen. Auch die kleinen Kugeln wurden von Anfang an angegriffen, ehe überhaupt ein Eindringen möglich gewesen wäre, nur äußerte sich an ihnen die Auflösung nicht in Form von Vertiefungen, sondern in Form von einer über größere Teile der Kugeloberfläche ausgedehnten Auflösung, die den Krümmungsradius vorerst wenig änderte, aber schließlich nach Auflösung des Berührungskegels zu einer gewissen Abplattung fuihrte. Mit dieser Abplattung ragte die kleine Kugel in die Vertiefung der größeren hinein. Die Vertiefung der größeren Kugel war an Umfang verhältnismäßig größer bei Berührung mit wesentlich kleineren Kugeln. Der Umfang der Vertiefung war gleich bei gleicher Größe der Kugeln. Es konnte also damit veranschaulicht werden, daß, wenn Löslichkeit beider Körper vorhanden ist, nur der kleinere in den größeren eindringen kann, selbst wenn sich ersterer durch Auflösung abgeplattet hat und infolgedessen der Krïmmungsradius dieser Stelle größer wird als an dem größeren Körper.

Außerdem ist dargetan, daß ein Eindringen nur unter Aufhebung der gegenseitigen Berïhrung der Spitzen der Berührungskegel erfolgen kann und daß ferner leicht zwisehen dem eindringenden Körper und der Eindruckswand Zwischenräume entstehen können (siehe auch S. 218 und 219 dieser Arbeit). Fiur die erforderliche Annäherung genügt das Gewicht des einen beweglichen Körpers vollkommen. Es bedarf keines Druckes, um die Berührungskegel zu zerstören. Es ist vielmehr anzunehmen, daß bei den natürlichen Geröllmassen durch geringfügige Bewegungen seismischen oder anderen Ursprungs die Gerölle gegeneinander verschoben werden können, so daß die Berïhrung der Kegelspitzen aufgehoben wird, die Kegel also nebeneinander zu liegen kommen und nun der Auflösung anheimfallen.

Die Erklärung für den auf S. 222 angeführten, oft zu beobachtenden geringeren Substanzverlust des einen Gerölls kann nunmehr nach den 
Versuchen und den voraufgegangenen Betrachtungen nur noch auf einen durch die. Gesteinsbeschaffenheit bedingten Löslichkeitsunterschied zurückgeführt werden. Worin diese Unterschiede bestehen mögen, ist noch ziemlich unklar. Jedenfalls glaube ich aus dem Umstande, daß auf karrenartig verwitterten Kalksteinen oft Kalzitadern hervorragen, daß Fossilreste aus Kalkspat aus dem Gestein herauswittern, folgern zu müssen, daß schon sehr kleine Unterschiede in der Reinheit der Kalkspatmasse, ihrer Korngröße, ihrer Porosität sowie der Beschaffenheit ihrer Oberfläche merkliche Unterschiede in der Auflösungsgeschwindigkeit hervorrufen.

Es ist allerdings zweifelhaft, ob die erwähnten Beispiele, bei denen doch wahrscheinlich die Bewegung des lösenden Wassers eine große Rolle spielt, mit der Auflösung an Kalkgeröllen identifizert werden können. Denn löst man in gleichen Mengen verdünnter Salzsäure zwei ungefähr gleich große und gleich schwere Stücke von Kalkstein mit verschiedenem Tongehalt, so findet man, daß sich das reinere Stuick schneller auflöst als dasjenige mit dem größeren unlöslichen Rückstande. Hierfür dürfte wohl der Umstand entscheidend sein, daß die tonigen Beimengen des letzteren eine kurze Zeitlang die Kalkspatunterlage schützen und dadurch die Einwirkung der Säure verzögern.

Was die Quarzitgerölle anbetrifft, so können wir nunmehr die in der Tabelle auf S. 217 zum Ausdruck gebrachte größere Häufigkeit von Eindrücken von Gangquarzitgeröllen in Sedimentquarzitgeröllen verstehen. Die Durchmesser der ersteren sind ja durchschnittlich kleiner als die der letzteren; folglich müssen die Gangquarzitgerölle auch häufiger vertiefte Eindrücke in den Sedimentquarzitgeröllen, in die sie eindringen, hinterlassen. Außerdem sind die Gangquarzitgerölle in der Überzahl, so daß also mehr Berührungsstellen zwischen Gang- und Sedimentquarziten vorhanden sein dürften als zwischen Geröllen der letzteren Art für sich allein.

Aber mehr noch als die Formunterschiede scheint ein nicht unbedeutender Unterschied der Löslichkeit zwischen den beiden Gesteinsarten von Einfluß zu sein. Die Eindrücke in den Sedimentquarzitgeröllen sind bedeutend tiefer und umfangreicher als die in den Gangquarzitgeröllen, und zwar selbst als die Eindrücke an sehr flachen Stellen der Gangquarzitgerölle, wo nur die Berührung mit einem gekrümmteren Geröll die Ursache zur Bildung der Eindrücke gewesen sein kann. Reste von eingedrungenen Geröllen habe ich in diesen Eindrücken nie beobachtet. Höchstwahrscheinlich beruht die größere Auflösungsgeschwindigkeit des Sedimentquarzits auf seiner feinkörnigeren Beschaffenheit, wodurch die Wahrscheinlichkeit erhöht wird, daß das Lösungsmittel mit leichter löslichen Flächen der einzelnen Kristalle in Berührung kommt, als bei den grobkörnigen Gangquarziten. Aus -diesem Umstande wird auch zu erklären sein, daß fast nur bei den Sedimentquarzitgeröllen die Oberfläche der Eindrïcke starke Unebenheiten aufweist, ja, man erhält den Eindruck, 
als ob gewisse wasserhelle Quarzkörnchen besonders häufig die Hervorragungen in ihnen bilden würden. Eine bestimmte kristallographische Orientierung dieser Körnchen scheint dabei das Maßgebende zu sein.

Im allgemeinen werden die Löslichkeitsunterschiede um so schärfer hervortreten, je schwächer das Lösungsmittel ist.

Als Letztes möchte ich noch einiges über die sutur- oder stylolithähnliche Verzahnung mancher Gerölle erwähnen. Schaad ([82], S. 48) hatte Erhebungen in den Eindruicken von Nagelfluhgeröllen gefunden und für stylolithenartige Bildungen gehalten, obgleich es ihm nicht geglïckt war, das den Eindruck erzeugende Nachbargeröll mit den entsprechenden Vertiefungen zu entdecken. RotHPLETz (55 und 58) hatte schon vorher an einigen mikroskopischen Präparaten nachgewiesen, daß mikroskkopisch kleine sehr feine Verzahnungen an der Berührungsstelle zweier Gerölle vorkommen. Die Rauhigkeit der Eindrucksoberfläche, deren Vertiefungen oft noch von geringen Resten des eingedrungenen Gerölls erfüllt sind, scheint ebenfalls auf eine innige Verbindung hinzudeuten. Die Beobachtungen ScHaAds beziehen sich aber auf sehr viel größere Vorsprünge, die nach ihm sogar eine Höhe von $8 \mathrm{~mm}$ erreichen können. Die Häufigkeit derartiger Bildungen ist indessen sehr gering, und ich halte es nicht für unmöglich, daß es sich dabei um Berührungskegel handeln könnte, denen auf dem anliegenden Geröll nicht eine entsprechende Vertiefung, sondern eine ganz ähnliche Erhöhung zugehören würde.

Aber auch eine sutur- oder stylolithenartige Verzahnung scheint mir durch einen rein chemischen Vorgang ohne Druckwirkung erklärt werden zu können. Haben sich z. B. durch Auflösung an den Benetzungsflächen die Gerölle so weit voneinander entfernt, bis sich die Flisssigkeit nicht mehr zwischen ihnen an der gesamten Angriffsfläche halten kann, sondern nur noch an den bisher stehengebliebenen Hervorragungen der einen Fläche mit der gegenüberliegenden Fläche in Berührung steht, so wird sich nur hier eine merkliche Auflösung vollziehen. Es werden gegenüber den Hervorragungen entsprechende Vertiefungen entstehen, so daß sich also hier derselbe Vorgang wie bei der Entstehung der Eindrücke im kleinen wiederholen würde.

Diese Art der Anschauung hat aber zur Voraussetzung, daß nach einiger Dauer des Auflösungsvorganges in dem betreffenden Eindruck eine Berührung der-Gerölle nicht vorhanden sein, daß es also nicht zur Bildung von Berührungskegeln kommen durfte. Die Gerölle mußten also auf andere Weise an gegenseitiger Beriihrung im Eindruck eine Zeitlang verhindert werden. In den natürlichen Konglomeraten ist stets damit zu rechnen, daß z. B. die einem größeren Geröll aufliegenden kleineren Gerölle sich oft gegenseitig behindern, mit ihrem ganzen Gewicht auf der Unterlage zu lasten und in einen hier entstehenden Eindruck einzudringen, wenn sie nicht schließlich durch Auflösung an den gemeinsamen Berührungspunkten den Halt verlieren und nachsinken können. Auch 
mögen Sandkörnchen, die sich zwischen den Geröllen einklemmen, sehr oft eine Bewegung der Gerölle erschweren, so daß in sehr vielen Fällen ein gewisser Abstand der beiden Körper in dem Eindruck vorhanden sein wird und etwa bestehende Berührungskegel wieder verschwinden können.

Die Richtigkeit dieser Vorstellung geht schon aus der Tatsache hervor, daß man selbst in ganz jungen, noch kaum verfestigten Geröll- und Kiesablagerungen sehr gut eine ganze Reihe von einzelnen Geröllen mit Vorsicht herausnehmen, ja ganze Höhlungen in ihnen ausgraben kann, obne daß die Gerölle der Decke sofort nachbrechen.

Wenn auch durch diese Erklärung die Möglichkeit gegeben ist, die Tatsache zu verstehen, daß einer Erhöhung des einen Gerölls eine Vertiefung in der Eindrucksfläche des anderen Gerölls entsprechen kann, so mögen jedoch Zweifel daran berechtigt sein, ob diese Erklärung auch für die Deutung jener mikroskopisch feinen Verzahnung anwendbar sein könne. Vielleicht ist sie eher auf die kristallographische Orientierung der einzelnen, das Gestein zusammensetzenden Kalkspatkörnchen und die verschiedene Angreifbarkeit ihrer verschiedenen Kristallflächen zurückzufihhren. Liegen sich z. B. zwei solcher Partikel mit den leicht angreifbaren Flächen gegenüber, so wird an ihnen die Auflösung gleich schnell vorschreiten, der Zwischenraum zwischen beiden wird sich vergrößern. Ist die Angreifbarkeit zweier danebenliegender Teilchen jedoch verschieden, so wird das schwerer lösliche die Hervorragung und das gegenüberliegende, wenn es noch stärker als das Nachbarteilchen gelöst wird, eine Vertiefung bilden. Bei nur sehr geringer Entfernung der Geröllflächen voneinander und der dadurch abgeschwächten Wasserzirkulation und Auflösung und bei nur sehr geringem unlöslichen Rückstande mag durch ein Aufeinanderpressen der Gerölle die Verzahnung eintreten.

Es könnte aber andererseits auch die Möglichkeit bestehen, daß in den von RotHPLETz beschriebenen Dünnschliffen gar nicht eine gegenseitige Verzahnung der beiden Gerölle vorliegt, sondern daß es sich hier nur um die Ausfüllung der mikroskopisch feinen Vertiefungen des einen Eindrucks durch eine dünne Zwischenschicht aus Kalzit handelt. Da ich aber leider das Material von RothPLETz im Original nicht kenne, muß ich mich hier nur auf die Erwähnung dieser Vermutung beschränken.

Tch möchte nicht verfehlen, im Anschluß hieran meine Bedenken gegen die zuletzt von G. WAGNER (89) vertretene Ansicht über die Entstehung der Stylolithen und Drucksuturen durch Lösung unter starkem Druck in festem Gestein zu äußern. Vermutlich wird man auch hier prinzipiell auf die Mitwirkung des Druckes verzichten können, vorausgesetzt natürlich, daß die Entstehung der Stylolithen im festen Gebirge als gesichert anzusehen ist. Sollten sich die von ScHaAd beobachteten Erhebungen in den Eindrücken wirklich als Stylolithen erweisen, so wäre damit ja auch der Analogieschluß berechtigt, daß sie sich in den bereits verfestigten Kalksteinbänken entwickelt haben werden. Aber vorläufig scheint mir dieser Schluß noch anfechtbar. 
Manche Beobachtungen, z. B. die Verzahnung zweier Versteinerungen an ihren Berührungsflächen, die sich doch bei einer weichen Beschaffenheit einer Schicht in diese hineingedrückt haben würden, und ferner die Durchbohrung von Versteinerungen und von Stylolithen ([89], S. 22 und 23) scheinen mir allerdings deutlich für den festen Zustand der Kalkbank zu sprechen. Gegen die Anwendung des Druckes möchte ich aber einwenden, daß sich auf den Stylolithenköpfen, die ja dem stärksten Druck ausgesetzt' sein sollen, analog den Berührungsstellen aufeinander gedrückter Gerölle, gar keine Fliussigkeit befinden könnte, zumal doch der tonige Lösungsrïckstand bzw. die Tonkappe auf dem Stylolithen wie eine Dichtungssscheibe wirken müßte. Die Diffusion wäre zum mindesten sehr erschwert und die Lösungsgeschwindigkeit gegenüber anderen Stellen herabgesetzt. Müßte nicht auch der Ton wie die Fliüssigkeit von dem Stylolithenkopf weggequetscht werden nach den Stellen hin, wo der geringste Druck herrseht, also nach den senkrechten Wänden? Ein Zwischenraum muß an diesen bestanden haben, damit das Lösungsmittel zugeführt oder abgeleitet werden konnte, »es findet hier sogar Absatz von Kalk statt « ([89], S. 28).

Nimmt man dagegen an, daß die ganze Last der hangenden Schichten auf eine die Suturspalte füllende Flüssigkeit gewirkt habe, so müßte der Druck in allen Teilen der Flächen gleich gewesen sein. Eine Steigerung der Löslichkeit müßte also ebenfalls die ganze Oberfläche des Stylolithen in gleicher Weise betreffen. Nun habenwir aber auf S. 212 gesehen, daß nach KöNIGSBERGER und MüLLEk eine Drucksteigerung die Löslichkeit des Kalziumkarbonats gar nicht merklich erhöht. Es käme also für die Entstehung der Vertiefungen nur noch die verschieden starke Löslichkeit verschiedenen Materials in Betracht, etwa das Auftreten von Ton auf den Stylolithenköpfen oder von Versteinerungen, die aus einem abweichenden Material bestehen.

\section{F. Allgemeine Ergebnisse und Folgerungen.}

Fassen wir die Ergebnisse der Untersuchungen über die Eindrücke in Geröllen und die sich daraus ergebenden Folgerungen noch einmal kurz zusammen, so können wir uns die Entwicklung des Lösungsvorganges etwa folgendermaßen vorstellen:

Eine merkliche Beeinflussung der Löslichkeit des Gesteins an den Berührungsstellen durch Druck, sei es durch Desaggregation oder durch Energieumwandlung, muß abgelehnt werden. Nur chemische Lösung durch das in dem kapillaren Hals um die Berührungsstelle herum sich haltende Wasser erklärt die beschränkte Umgrenzung des Auflösungsgebietes. Nur chemische Lösung gibt die Möglichkeit, die Beriihrungskegel zu verstehen. Diese müssen sich bilden, solange eine Auflösung bei gegenseitiger Berïhrung der Gerölle stattfindet. Da nun aber in der Natur Eindrücke mit gut ausgebildeten Berïhrungskegeln in älteren 
als jungdiluvialen Konglomeraten verhältnismäßig selten sind, muß angenommen werden, daB entweder an den Lösungsstellen keine Beriihrung bestanden hat, oder daß eine anfängliche Bildung von Berïhrungskegeln durch deren Auflösung wieder aufgehoben wurde. Berührungskegel sind daher das charakteristische Merkmal für das Jugendstadium in der Entwicklung der Eindrücke und finden sich dementsprechend an Kalkgeröllen hauptsächlich in den jüngsten Ablagerungen. Ihr Vorkommen an alten Kieselsäuregesteinen erklärt sich durch ihre geringere Löslichkeit. Die Auflösung kann sofort nach der Ablagerung des Gerölls anfangen. Der Beginn der Auflösung allein an der eng begrenzten Stelle des Eindrucks kann jedoch erst für die Zeit nach der Entstehung einer einigermaßen mächtigen, durchlässigen Ubberdeckung, die die Wasserzufuhr regelt, angenommen werden. Der Abfluß darf nicht geringer sein als der Zufluß. Das Gegenteil würde eine Füllung sämtlicher Zwischenräume mit Wasser herbeiführen und die Auflösung auf die gesamte Gerölloberfläche in gleich starkem Maße ausdehnen. Das zweite oder Reifestadium der Entwicklung ist meist vor Eintritt dieses Zustandes, hervorgerufen durch Erfüllung mit Grundwasser, beendet gewesen.

Diese Reihenfolge der Vorgänge ist bei kontinentalen Geröllbildungen ziemlich allgemein zu erwarten. Sie kann aber auch bei unzweifelhaften Kï̈stenkonglomeraten oder submarinen Bildungen wie den Oolithen vorkommen, wenn diese für längere Zeit dem Bereich des Meerwassers entzogen waren, bevor sich das chemische Bindemittel abgeschieden und die Ablagerungen verfestigt hatte. Denn die Bildung der tiefen Ein. drücke z. B. in der Rigi-Nagelfluh scheint mir nur- denkbar, wenn die Gerölle noch die Möglichkeit hatten, in den einmal entstandenen Eindruck nachzudringen.

Führte der Fortgang der Ablagerung einer marinen Geröllmasse mehr und mehr zur Verlandung, drängten die Geröllablagerungen das Meer zurïck, so entstanden in den obersten Regionen, in denen des Sickerwassers, die Eindrücke, in denen des Grundwassers dagegen sammelten sich die konzentrierten Lösungen an. Die Grenze beider verschiebt sich nach oben mit dem Absinken der Schichten. Erst nachfolgende Hebungen mit ihrem Gefolge von Klüftungen und Pressungen konnten zu einem Sinken des Grundwasserspiegels, zur Verdunstung des Wassers und Kristallisation der gelösten Substanzen führen. Der Druck der tektonischen Bewegungen drückte die kleineren und die stärker gekrümmten Gerölle in die entsprechend weiteren Vertiefungen in den größeren oder flacheren Geröllen hinein. Die Gerölle reiben sich aneinander, sie reiben sich an dem festen Bindemittel und auch an der Zwischenhaut oder der Kalzitschicht in den Eindrücken und hinterlassen überall die Rutschstreifen und Rutschglättung. Durch den Druck werden die Gerölle häufig zerquetscht. 


\section{Anhang.}

Da das Manuskript dieser Arbeit schon Ende Juli 1919 an die Redaktion eingeschickt wurde, war es mir leider nicht möglich, die neueste Veröffentlichung 》Utber Gerölle mit Eindrïcken « in der Arbeit selbst zu berücksichtigen. P. Kessler (111), dessen Aufsatz, wie schon aus dem Titel hervorgeht, keineswegs eine möglichst vollständige Behandlung des Stoffes beabsichtigt, bringt einige Angaben von Literatur, die mir bisher leider entgangen waren und die ich gern noch in dem Nachtrag zu meinem Literaturverzeichnis mit aufgenommen habe. Außerdem bin ich sehr erfreut darüber, daß die Liste der Vorkommen von Eindrücken nun auch durch Funde im Alluvium erweitert worden ist, so daß sie nun bereits in allen Formationen vom Devon an (KESsLer meint vom Karbon an) mit Ausnahme des Jura bekannt geworden sind. Zweifellos werden sich auch Eindrücke in Geröllen, Versteinerungen oder Oolithkörnern dieser Formation bzw. in den ältesten Formationen noch nachweisen lassen. Obgleich KESsLER durch seine Beobachtungen ebenfalls zu der Überzeugung geführt wurde, daß die Erscheinung der Eindrücke nur durch rein chemische Auflösung zu erklären sei, so beruhen doch einige seiner Folgerungen auf irrigen Annahmen. Er glaubte, daß die Eindrïcke in den Geröllen des Hauptkonglomerates von Lascemborn erst durch die erhöhte Wasserzirkulation als Folge von tektonischen Zerrüttungen und Heraushebung über den Grundwasserspiegel sich entwickelt hätten, wogegen ich für den Buntsandstein zu zeigen versucht habe, daß die Verwerfungen ein Konglomerat zerrütteten, in dem sich die Eindrücke, in denen die Nachbargerölle durch Kieselsäure fest verkittet waren, längst gebildet hatten, und daß die Verkittung so stark gewesen sein mußte, da $B$ das eingedrungene Geröll eher zerbrach, als sich aus der Vertiefung herauslöste. Es kann also aus dem Lascemborner Vorkommen nicht geschlossen werden, daß Zerrïttungen mit nachfolgender erhöhter Wasserzirkulation die Ursache dafür sei, daß man Gerölle mit Eindrücken hauptsächlich an gestörten Stellen anträfe und daß überhaupt Eindrücke in dieser Periode entstehen könnten. Ich möchte auch hier nochmals darauf hinweisen, daß für die tertiäre alpine Nagelfluh ebenfalls in unzweideutigster Weise eine Entstehung der Eindrücke schon vor Beginn der tektonischen Bewegungen und vor der Verfestigung der Konglomerate aus der Tatsache zu folgern ist, daß die tektonischen Bewegungen nicht nur Rutschstreifung auf den Geröllen und dem Bindemittel, sondern auch auf dem in den Eindrücken oft vorhandenen Kalzithäutchen hinterlassen haben. Die Eindrücke müssen also vorhanden gewesen sein, ehe die Bewegungen sich vollzogen. Für die jungen, noch nicht völlig verfestigten Kieslager nimmt KEssLeR allerdings wie ich eine Entstehung der Eindrücke in einer Zeit an, in der das Material eben wenigstens $z$. T. noch die ursprüngliche Lockerheit besitzt, und hält die Eindrïcke auch für ein Produkt des Sickerwassers. 
Welche Schwierigkeiten stehen aber der Annahme entgegen, daß der Bildungsvorgang bei Eindrücken in Geröllen aller älteren Konglomerate nicht derselbe gewesen sein dürfte? Meines Erachtens wäre es z. B. eher angebracht, aus dem Vorhandensein von Eindrücken in den Buntsandsteinkonglomeraten zu schließen, daß letztere sich währènd oder kurz nach ihrem Absatze oberhalb des Grundwasserspiegels, und zwar für lange Zeit, befunden haben müssen, als umgekehrt etwa von der Annahme einer marinen Entstehung auszugehen und danach die Bildung der Eindrücke in eine Zeit nach einer tektonischen Zerrüttung der ehemals bereits verfestigt gewesenen Schichten zu verlegen. Am Schlusse seiner Arbeit beweist KESsLer übrigens auch für das Konglomerat des Letzenberges, allerdings im Widerspruch mit dem früheren Vergleich mit dem Hauptkonglomerat von Lascemborn, die Entstehung der Eindrücke unmittelbar nach der Ablagerung der Gerölle.

\section{Erklärung der Tafel IV.}

Fig. 1. Gangquarzitgeröll mit Eindrücken aus dem Hauptkonglomerat von St. Odilien bei Barr am Ostrande der Vogesen.

Fig. 2. Gangquarzitgeröll mit Eindruck aus dem Eckschen Konglomerat von Schramberg-Sulgau im Schwarzwalde.

Fig. 3. Muschelkalkgeröll mit Eindrücken und Berührungskegeln sowie Kalzithaut aus dem jungdiluvialen Neckarschuttkegel. Kiesgrube am Pleikartsförsterhof westlich Heidelberg.

Fig. 4. Muschelkalkgeröll, dessen tine Seite oberhalb der punktierten Linie stark aufgelöst ist, mit stehengebliebenem Berührungskegel. Ein eigentlicher Eindruck ist nicht zu sehen. Jungdiluvialer Neckarschuttkegel, Kiesgrube südlich Eppelheim bei Heidelberg.

Fig. 5. Muschelkalkgeröll mit Eindruck und Berührungskegel, dessen Oberfläche korrodiert ist. $a=$ Abflußrinne des Wassers. Die unterhöhlte Kalzitschicht um den Eindruck herum hebt sich hier deutlich von der eingetieften Unterlage ab. Jungdiluvialer Neckarschuttkegel, Kiesgrube beim Hegenichshof bei Heidelberg. 


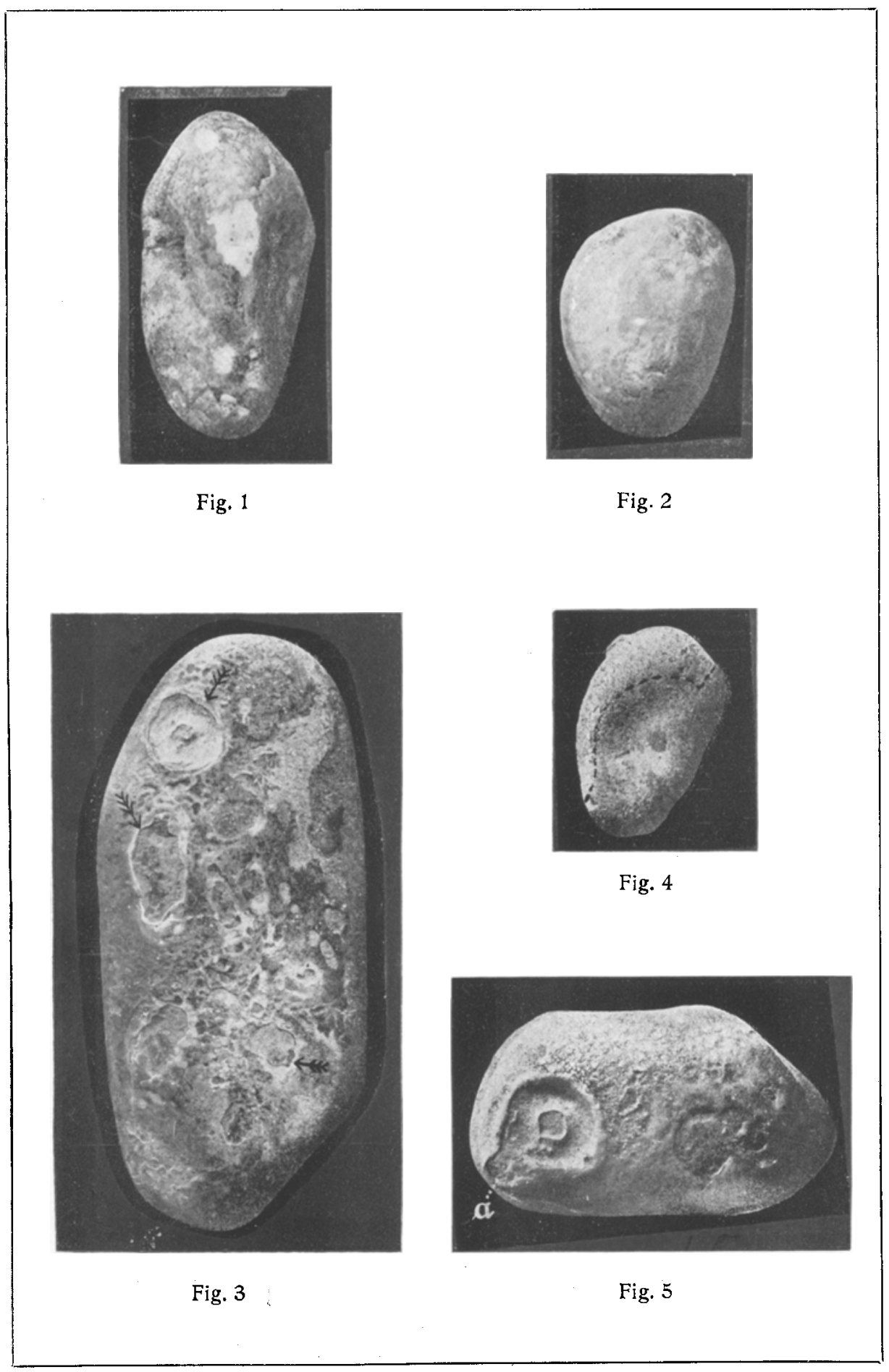

$\mathrm{Kum} \mathrm{m}$.

Verlag von Wilhelm Engelmann in Leipzig. 